\title{
Empresas que se destacam pela qualidade das informações a seus usuários externos também se destacam pela utilização de artefatos modernos de contabilidade gerencial?
}

\section{Do companies who stand out for information quality for external users also stand out for the use of modern management accounting artifacts?}

\author{
Reinaldo Guerreiro \\ Professor Titular da Faculdade de Economia, Administração e Contabilidade da Universidade de São Paulo do Departamento de Contabilidade e Atuária \\ E-mail: reiguerr@usp.br
}

Edgard Bruno Cornachione Júnior

Professor Titular da Faculdade de Economia, Administração e Contabilidade da Universidade de São Paulo do Departamento de Contabilidade e Atuária

E-mail: cornachione@gmail.com

Dione Olesczuk Soutes

Professora Efetiva do Departamento de Ciências Contábeis da Faculdade UNIOESTE - Universidade Estadual do Oeste do Paraná

E-mail: dioneosoutes@gmail.com

Recebido em 22.06.2010 - Aceito em 15.09.2010 - $2^{a}$ versão aceita em 21.12.2010

\section{RESUMO}

Estudos empíricos têm indicado baixo grau de utilização de artefatos modernos de Contabilidade Gerencial propostos pela literatura. No âmbito teórico, a teoria da contabilidade engloba o pressuposto de que a contabilidade deveria atender eficazmente os seus usuários externos e internos. Este estudo tem dois objetivos principais: avaliar se (a) empresas brasileiras que se destacam pelo seu porte na economia brasileira utilizam artefatos modernos de Contabilidade Gerencial e (b) empresas que se destacam pela qualidade de suas informações aos usuários externos, também, se destacam pela maior utilização de artefatos modernos de Contabilidade Gerencial de apoio a usuários internos. Uma amostra de 90 empresas foi examinada, selecionadas dentre empresas listadas entre as 500 maiores empresas (edição de 2005 de Melhores e Maiores) e dentre o rol de empresas que foram indicadas ao Prêmio ANEFAC-FIPECAFI-SERASA, Troféu Transparência, entre os anos-base de 1996 a 2004. Dados foram coletados por meio de questionário endereçado ao gestor da área de Contabilidade Gerencial, contendo questões relativas ao grau de utilização de artefatos tradicionais e modernos de Contabilidade Gerencial. Os resultados do estudo demonstram que (a) as empresas da amostra utilizam artefatos modernos de Contabilidade Gerencial e (b) a amostra de empresas indicadas para o prêmio não se diferencia, em termos de utilização de artefatos modernos de Contabilidade Gerencial, do grupo das demais empresas pesquisadas.

Palavras-chave: Contabilidade Gerencial. Artefatos modernos. Empresas brasileiras.

\section{ABSTRACT}

Empirical studies have indicated low levels of adoption of modern management accounting artifacts, as 
suggested by the literature. Accounting theory encompasses the assumption that accounting should effectively assist both internal and external users. The present study aims at two main goals: to evaluate whether (a) large Brazilian companies actually use modern management accounting artifacts; and (b) companies that stand out by the quality of information disclosed to external users also stand out in terms of how they assist their internal users. A sample of 90 companies is examined, selected from the 500 largest companies in Brazil (2005 edition of "Melhores e Maiores") and from the nominees for the ANEFAC-FIPECAFI-SERASA Transparency Award (from 1996 to 2004). Data was collected from a survey submitted to the head of management accounting area, with items related to the level of use of both traditional and modern management accounting artifacts. Findings demonstrate that (a) the sample companies do use modern management accounting artifacts; and (b) the companies nominated to the award do not differ from the other companies in terms of use of such artifacts..

Keywords: Management accounting. Modern artifacts. Brazilian companies.

\section{INTRODUÇÃO}

Após a publicação do livro Relevance Lost, de Thomas Johnson e Robert S. Kaplan, em 1987, intensificou-se o desenvolvimento e as proposições de novos artefatos de Contabilidade Gerencial, destacando-se o Sistema de Custeio Baseado em Atividades (ABC), a Gestão Baseada em Atividades (ABM), o Sistema de Gestão Econômica (Gecon), o $B a$ lanced Scorecard, o Custeio Meta, a Teoria das Restrições, dentre outros.

Apesar do desenvolvimento desses novos artefatos, autores e pesquisadores têm alertado para o que se pode denominar "estabilidade da Contabilidade Gerencial", afirmando que a pesquisa contábil tem causado pouco impacto na prática das organizações. Alguns desses trabalhos que verificam o gap existente entre teoria e prática são os de: Scapens (1994), Otley (1985), Choudhury (1986), Johnson e Kaplan (1987), Edwards e Emmanuel (1990), Cohen e Paquete (1991), Brigth et al. (1992), Emore e Ness (1991), Green e Amenkhienan (1992), Ask e Ax (1992), Drury et al. (1993), Drury e Tayles (1995), Evans e Ashworth (1996) e Granlund (2001).

Os resultados das pesquisas relatadas indicam um acentuado descompasso entre teoria e prática da Contabilidade Gerencial e um baixo grau de implementação de novos artefatos gerenciais, mesmo em se tratando daqueles com maior divulgação, como, por exemplo, o sistema de custeio baseado em atividades.
Considerada a importância do estudo do referido gap na realidade brasileira, foi estabelecido o primeiro objetivo deste trabalho, que diz respeito a identificar se empresas brasileiras de uma amostra selecionada, que se destacam pelo seu porte na economia brasileira, utilizam artefatos modernos de Contabilidade Gerencial. Para o atendimento desse objetivo foi pesquisado o universo de empresas atuantes no mercado brasileiro listadas entre as 500 maiores empresas em vendas, do caderno Melhores e Maiores da Revista Exame de Julho de 2005 (ano base 2004), bem como as empresas que foram indicadas ao Prêmio ANEFAC-FIPECAFI-SERASA, Troféu Transparência, entre os anos-base de 1996 a 2004.

Nos estudos da teoria contábil, como, por exemplo, na obra de Hendriksen e Van Breda (1992) e de Iudícibus (1997), é enfatizado que a contabilidade tem como objetivo atender, adequadamente, os seus diferentes usuários. No campo da teoria e da prática contábil têm se consolidado os campos de atuação da contabilidade financeira e da Contabilidade Gerencial objetivando atender as demandas dos usuários externos e usuários internos. Assim, o segundo objetivo do presente estudo diz respeito a investigar se empresas de uma amostra selecionada, que se destacam pela qualidade de suas informações aos usuários externos, também se destacariam no atendi- 
mento de seus usuários internos, por meio de maior adoção de artefatos modernos de Contabilidade Gerencial, relativamente às demais empresas. Deve ser observado que o destaque no atendimento de usuários internos tem como premissa o grau de utilização de artefatos modernos de Contabilidade Gerencial.

Essa indagação foi inspirada na pesquisa desenvolvida por Carr, Mak e Needham (1997), que identificou as diferenças relativas à estratégia, práticas gerenciais e sistema de relatórios gerenciais entre empresas certificadas nos padrões da entidade International Organization for Standardization (ISO) e empresas não certificadas nesses padrões. A pressuposição estabelecida pelos autores é de que, considerando que a certificação ISO indica um aumento de ênfase em qualidade, o sistema de relatórios gerenciais sobre atividades de qualidade das organizações que obtiveram essa certificação deveria refletir essa ênfase em qualidade. Para o atendimento do segundo objetivo, somente as empresas pertencentes ao segundo grupo (indicadas ao Prêmio ANEFAC-FIPECAFI-SERASA, Troféu Transparência) foram investigadas.
No âmbito deste trabalho, conceituamse, como artefato de Contabilidade Gerencial, modelos de gestão, sistemas de gestão, sistemas de informação e ainda conceitos de mensuração e avaliação de desempenho, que possam ser utilizados pelos profissionais da Contabilidade Gerencial no exercício de suas funções. São caracterizados como artefatos modernos de Contabilidade Gerencial os artefatos que satisfaçam aos objetivos dos estágios 3 e 4 de Contabilidade Gerencial propostos pelo International Federation of Accountants (IFAC, 1998).

Este trabalho está subdividido em mais cinco tópicos além desta introdução. $\mathrm{O}$ segundo tópico apresenta a evolução da Contabilidade Gerencial conforme estudo efetuado pelo IFAC (1998). O terceiro, a revisão de literatura, abordando estudos teóricos e práticos sobre a utilização de artefatos de Contabilidade Gerencial. O quarto tópico apresenta a pesquisa desenvolvida, abordando o planejamento de pesquisa, os resultados encontrados e a análise desses resultados. O quinto tópico trata das considerações finais do estudo e, no último tópico, são relacionadas às referências bibliográficas utilizadas.

\section{REVISÃO DE LITERATURA E ESTRUTURA CONCEITUAL}

\subsection{A evolução da Contabilidade Gerencial na perspectiva do IFAC}

Em março de 1998, o International Federation of Accountants (IFAC) atualizou o trabalho originalmente publicado em 1989 sobre a atividade conhecida como Contabilidade Gerencial. Esse trabalho foi desenvolvido na forma de uma estrutura conceitual, apresentando os objetivos, as tarefas e os parâmetros da Contabilidade Gerencial. Mostra, também, o processo de evolução percebido no campo de atuação da Contabilidade Gerencial.

O estudo IFAC (1998) identifica quatro estágios de evolução no campo da Contabili- dade Gerencial. O primeiro estágio durou até 1950 e, nesse período, o objetivo principal foi caracterizado como a determinação de custo e controle financeiro, pelo uso da tecnologia de orçamento e contabilidade de custos. O segundo estágio foi de 1950 até 1965 e, nesse período, a Contabilidade Gerencial esteve concentrada no fornecimento de informação para planejamento e controle gerencial, pelo uso das técnicas de análise de decisões e contabilidade por responsabilidade. O terceiro estágio iniciou-se em 1965 e durou até 1985; nesse período, a atenção esteve voltada para a redução de perdas de recursos nos processos, sendo enfatizada a análise de processos e gerenciamento de custos. O último estágio da 
Contabilidade Gerencial (IFAC, 1998) identificado teve início em 1985 e dura até os dias de hoje, sendo seu foco centrado na geração e/ou criação de valor pelo uso efetivo dos recursos, com a utilização de direcionadores de criação de valor para o consumidor, valor para o acionista e inovação organizacional.

O estudo discute, fundamentalmente, a conceituação e o campo de atuação da Contabilidade Gerencial, as diferenças existentes entre os seus diversos estágios evolutivos, o relacionamento entre a Contabilidade Gerencial e o processo de gestão, e uma proposição de estrutura conceitual. É importante observar que, naquele estudo, não são enfatizadas as práticas de Contabilidade Gerencial utilizadas em cada estágio. É possível, no entanto, a partir do entendimento das características e objetivos de cada estágio, efetuar correlação entre os estágios e os artefatos de Contabilidade Gerencial requeridos, conforme apresentado no tópico 3.1.

\subsection{Utilização de artefatos da Contabilidade Gerencial}

A literatura referente à Contabilidade Gerencial é muito vasta. Diversos estudos têm sido efetuados com o objetivo de investigar o estágio de desenvolvimento conceitual e prático dos artefatos da Contabilidade Gerencial. Tendo em vista a quantidade e diversidade desses estudos, nesse tópico são apresentados, em sequência cronológica, aqueles que contribuíram especificamente para o desenvolvimento deste trabalho. Inicialmente, apresentam-se os estudos realizados no exterior e, no final da seção, os estudos realizados no Brasil.

Drury e Tayles (1995) desenvolveram trabalho de análise de pesquisas empíricas do tipo survey, objetivando identificar e comentar as principais conclusões dos estudos $\mathrm{e}$ discutir questões relevantes que deveriam ser objeto de pesquisas mais profundas baseadas em estudo de casos. O material coletado foi classificado em cinco grandes blocos de aná- lise: (i) "o uso extensivo de full costs para a tomada de decisão"; (ii) "acuracidade dos sistemas de custeio de produtos"; (iii) "a mentalidade de contabilidade financeira"; (iv) "a implementação do princípio da controlabilidade" e (v) "mudanças nos sistemas de Contabilidade Gerencial". Os resultados apresentados no estudo de Drury e Tayles (1995) demonstram que - até 1995 - as empresas estavam utilizando sistemas de Contabilidade Gerencial passíveis de severas críticas se comparados com a teoria.

Bjornenak (1997) efetuou estudo baseado em livros textos de contabilidade de custos utilizados na Noruega desde 1936 até 1996. Esse levantamento bibliográfico foi comparado com achados de três pesquisas empíricas. Os achados do estudo indicaram que, na Noruega, a contabilidade de custos vivenciou três fases. A primeira foi fortemente influenciada pelo modelo alemão de contabilidade de custos; uma segunda fase demonstra uma mistura de influências e a terceira indica, claramente, o predomínio da influência norteamericana. O estudo mostrou, também, como as mudanças nos conteúdos dos livros textos que correspondem às mudanças das práticas empresariais desempenham um importante papel na institucionalização dessas práticas.

A tendência da pesquisa em Contabilidade Gerencial na escola norte-americana foi explorada por Shields (1997), que examinou 152 artigos publicados por autores norteamericanos em seis revistas internacionais de destaque na área contábil. $O$ autor descobriu que a grande maioria dos artigos estava relacionada com "sistemas de controle gerencial" e os tópicos considerados modernos (SHIELDS, 1997) eram relativamente poucos (quatro publicações sobre custeio baseado em atividades, quatro publicações sobre Just-in-Time e duas publicações sobre benchmarking).

Chenhall e Langfield-Smith (1998a) desenvolveram pesquisa procurando identificar o papel que o gestor da Contabilidade Gerencial executou no processo de mudança 
de sistemas de avaliação de desempenho. $\mathrm{O}$ resultado do estudo indicou três fatores como influenciando o grau de participação dos contadores gerenciais no processo de mudanças: (i) uma visão compartilhada entre os contadores e os gestores a respeito do papel que a Contabilidade Gerencial pode desempenhar no processo de mudanças; (ii) o fato de que os contadores gerenciais estão menos dispostos a participar do processo de mudança quando os gerentes operacionais não dão o devido apoio ao desenvolvimento de inovações na Contabilidade Gerencial e (iii) a existência de um forte patrocinador para as mudanças exigidas na Contabilidade Gerencial (principalmente na presença de fraco apoio de gestores operacionais às mudanças em desenvolvimento).

Bjornenak e Olson (1999) desenvolveram estudo a partir de revisão de literatura sobre Contabilidade Gerencial com o objetivo de analisar as características de novos modelos propostos na literatura. Os autores focam as inovações como modelos ou "pacotes" de técnicas e ideias. O conceito de modelo engloba diferentes características e dependendo de como se agrupam ou se analisam determinadas características, novos sistemas podem ser estruturados. Foi utilizada estrutura genérica proposta pelos autores em que as inovações em Contabilidade Gerencial são classificadas pelas dimensões de escopo e de sistema. Em seguida, a dimensão de escopo se subdivide em: (i) objetos descritivos (objetos de interesse de análise); (ii) fatores que causam variabilidade e (iii) tempo. A dimensão de sistema é subdividida em: (i) tempo de duração (permanentes ou temporários) e (ii) aspectos relacionados com o atendimento informacional aos usuários. Os modelos analisados e classificados segundo a estrutura proposta foram: Sistema de Custeio Baseado em Atividades (ABC), Gestão Baseada em Atividades, Sistema de Informações Distribuídas, Balanced Scorecard, Custeio do Ciclo de Vida, Custeio Meta e Contabilidade para
Gestão Estratégica.

Guilding, Cravens e Tayles (2000) investigaram a utilização e o respectivo mérito de um conjunto de doze práticas de Contabilidade Gerencial Estratégica (strategic management accounting) em organizações do Reino Unido, dos Estados Unidos e da Nova Zelândia. O estudo efetua reflexões e proposições no campo relativamente desconhecido, segundo os autores, denominado "Contabilidade Gerencial estratégica”. As práticas estudadas foram: custeio de atributos, orçamentação do valor da marca, monitoramento do valor da marca, avaliação do custo de concorrente, monitoramento da posição competitiva, avaliação de concorrentes com base em informações contábeis públicas, custeio da vida de produtos, custo da qualidade, custeio estratégico, apreçamento estratégico, custeio meta, custeio da cadeia de abastecimento.

A pesquisa de Innes, Mitchell e Sinclair (2000) comparou os resultados de duas pesquisas empíricas sobre a utilização do sistema de custeio baseado em atividades por grandes companhias do Reino Unido realizadas em 1994 e 1999. Esse estudo focou as mudanças que ocorreram na adoção do sistema $\mathrm{ABC}$ no período de cinco anos. Os resultados desse estudo comparativo permitem analisar a natureza dos sistemas em uso, o seu desenho, o uso que é feito deles e a avaliação que os seus usuários efetuam desse sistema em termos de sua eficácia.

Maher (2000) analisou a evolução da educação em Contabilidade Gerencial nos Estados Unidos, do ponto de vista de percepção pessoal. Em seu estudo, o autor faz referência ao livro de Horngren et al. (2000) que reporta os novos tópicos de contabilidade de custos e o número de páginas dedicadas a cada tópico. Esses novos tópicos são: Custeio Baseado em Atividades/Gestão Baseada em Atividades, Just-in-Time, Balanced Scorecard, Análise de Rentabilidade de Clientes, EVA, Kaizen, Custeio do Ciclo de Vida, Medidas Não Financeiras, Custos de Qualidade e Tempo, Análise de 
Rentabilidade Estratégica, Cadeia de Abastecimento, Custeio Meta, Contabilidade de Ganhos e Cadeia de Valor. O autor menciona que a introdução dessas inovações, bem como a expansão da Contabilidade Gerencial nos currículos escolares, demonstra que esse é um campo que está "vivo e muito bem na academia”.

Haldma e Lääts (2002) efetuaram estudo da utilização de artefatos de Contabilidade Gerencial em amostra de empresas de manufatura da Estônia, enquanto Hughes e Gjerde (2003) efetuaram pesquisa empírica semelhante com uma amostra de empresas nos Estados Unidos.

O estudo de Baines e Langfield-Smith (2003), fundamentado em pesquisa com empresas industriais e utilizando modelagem de equações estruturais, procurou examinar as relações entre as mudanças no ambiente competitivo e um rol de variáveis organizacionais como antecedentes de mudanças em sistemas de Contabilidade Gerenciais. Nesse estudo, com base em trabalho de Chenhall e Langfield-Smith (1998b), foram classificados como artefatos de Contabilidade Gerencial mais avançados: (i) programas de melhoria da qualidade; (ii) análise de rentabilidade de produtos; (iii) benchmarking; (iv) análise de rentabilidade de clientes; (v) análise do valor para o acionista (EVA); (vi) custeio meta; (vii) custeio baseado em atividades; (viii) gestão baseada em atividades; (ix) análise da cadeia de valor e (x) análise do ciclo de vida do produto.

Sulaiman, Ahmad e Alwi (2004) desenvolveram investigação, baseada em revisão de literatura de pesquisas empíricas, sobre algumas práticas de Contabilidade Gerencial em quatro países asiáticos (Singapura, Malásia, China e Índia). Os autores classificaram como práticas tradicionais: (i) custo padrão; (ii) análise de sensibilidade entre o custo, o volume e o lucro; (iii) retorno sobre o investimento e (iv) orçamento. As práticas contemporâneas estudadas foram: (i) gestão da qualidade total (TQM); (ii) custeio baseado em atividades (ABC); (iii) custeio meta (target costing) e (iv) balanced scorecard (BSC). Os resultados indicam que o uso de práticas contemporâneas nos países estudados ainda é incipiente.

Adelegan (2006) desenvolveu estudo nas empresas da Nigéria e Szychta (2006) efetuou estudo com amostra de empresas polonesas, analisando o grau de evolução na utilização de alguns artefatos de Contabilidade Gerencial, em determinado período de tempo (1999 a 2005).

No estudo teórico sobre gestão de custos, McNair (2007) menciona que a primeira resposta à demanda de novas formas de informação contábil foi o sistema de custeio baseado em atividades e que, no final da década de 90, ocorre uma explosão de novas ferramentas, sendo apresentada uma lista de sistemas considerados modernos. $\mathrm{O}$ autor efetua uma segregação desses sistemas em duas perspectivas: a operacional e a estratégica. Na perspectiva operacional são listados: o custeio de fluxo de processo, a gestão baseada em atividades; a teoria das restrições; a gestão de custos de capacidade; o orçamento baseado em atividades; o custeio baseado em atividades; o custeio just-in-time e o custeio backflush. Na perspectiva estratégica são apresentados: o modelo de criação de valor; a gestão estratégica de custos; a empresa extendida; o custeio do ciclo de vida e a economic value added (EVA).

Abdel-Kader e Luther (2008) desenvolveram estudo em empresas industriais inglesas, fundamentado na teoria da contingência, objetivando buscar entender o impacto de variáveis ambientais na finalidade dos sistemas de Contabilidade Gerencial. Os autores concluem que existe significativo impacto de variáveis ambientais, incerteza ambiental, poder do cliente, características organizacionais, estratégia competitiva, descentralização, tamanho, complexidade operacional, tecnologia, TQM e JIT e durabilidade dos produ- 
tos, nos objetivos dos sistemas de Contabilidade Gerencial adotados pelas empresas. Os objetivos fixados foram inspirados no estudo do IFAC (1998), sendo considerados os clusters de objetivos: (i) determinação de custos e controle financeiro; (ii) planejamento e controle gerencial; (iii) redução de perdas de recursos e (iv) criação de valor pelo uso eficiente de recursos.

Himme (2010) desenvolveu pesquisa do tipo survey em empresas na Alemanha sobre instrumentos de gestão de custos. Os sistemas pesquisados foram: benchmarking (59\%); reengenharia (32\%); custeio meta (30\%); análise de valor de custos indiretos (23\%); análise de valor (12\%); orçamento base zero $(6 \%)$ e custeio do ciclo de vida de produtos (5\%).

No que diz respeito a pesquisas sobre artefatos de Contabilidade Gerencial no Brasil, observa-se que têm sido realizadas mais recentemente. Em estudo sobre o estágio evolutivo da Contabilidade Gerencial em amostra de empresas brasileiras, Soutes e Zen (2005) propõem segregação dos artefatos da Contabilidade Gerencial entre os estágios caracterizados no estudo do IFAC (1998).

Frezatti (2005) desenvolveu um estudo em um universo de empresas brasileiras de médio e grande porte com o objetivo de avaliar a aderência conceitual entre as práticas gerenciais utilizadas pelas empresas e a base teórica da Contabilidade Gerencial. O estudo baseado em análise de clusters indica que as empresas estão em estágios muito diferentes no que diz respeito à utilização das práticas da Contabilidade Gerencial.

O trabalho de Cardoso, Pereira e Guerreiro (2007) teve como objetivo traçar um perfil da pesquisa em custos no âmbito da temática de contabilidade e controle gerencial do ENANPAD, desde a sua inauguração como área autônoma em 1998 até 2003. A análise consistiu inicialmente na revisão de 170 artigos aceitos na área temática e, depois, na seleção dos 32 artigos específicos de custos. Foram pesquisados os temas abordados, os métodos de pesquisa adotados, os segmentos econômicos estudados, a filiação acadêmica dos autores e o tipo de bibliografia consultada. Os resultados evidenciaram forte crescimento quantitativo da temática de contabilidade, passando do patamar de 40 trabalhos submetidos em 1998 para 191 trabalhos em 2003. Segundo os autores os resultados indicam que esse crescimento quantitativo não foi acompanhado, na mesma proporção, pelo crescimento qualitativo dos trabalhos na área de custos.

Oyadomari et al. (2008) desenvolveram estudo exploratório num universo de 27 empresas buscando entender o processo de adoção de artefatos de Contabilidade Gerencial tendo como referencial teórico a nova teoria institucional. Os resultados desse estudo indicam que a adoção é do tipo cerimonial, que o comportamento mimético é importante no processo de adoção e que o processo de obtenção do conhecimento dos novos instrumentos ocorre, preponderantemente, pela forma de socialização do conhecimento. Destaque-se, ainda, que as consultorias têm um papel importante na adoção dos artefatos e que o mecanismo coercitivo por parte da diretoria não é relevante.

Santos et al. (2009) desenvolveram estudo de acordo com a premissa que a escolha dos artefatos de controle gerencial está diretamente influenciada pelo estilo gerencial do gestor, sendo esse caracterizado pela definição de padrões e formas de comunicação estabelecidos. O objetivo do estudo foi evidenciar a influência do estilo gerencial na adoção dos artefatos de controle gerencial nas organizações sem fins lucrativos do setor de meio ambiente. Foram pesquisadas empresas cadastradas em 2008 no Mapa do Terceiro Setor da cidade de Curitiba. Os resultados do estudo indicam que entre as entidades sem fins lucrativos, a existência dos Estilos Gerencial Consultivo e Participativo, sendo em sua maioria Consultivo, bem como a sua influência na adoção de diversos artefatos de controle gerencial, evi- 
denciados no resultado da pesquisa.

Teixeira et al. (2009) desenvolveram pesquisa exploratória objetivando identificar se as empresas do Estado do Espírito Santo utilizam artefatos modernos de Contabilidade Gerencial, bem como a relação entre a utilização de artefatos tradicionais e modernos com o êxito econômico das empresas da amostra. De acordo com os autores, foram encontradas evidências que sugerem que as empresas do Estado do Espírito Santo utilizam ferramentas consideradas tradicionais de Contabilidade Gerencial, porém não foram encontrados indícios de relação entre a utilização de artefatos considerados tradicionais e modernos e o êxito econômico das empresas da amostra.

Beuren e Erfurth (2010) buscaram identificar temas que serão abordados no futuro em pesquisas de Contabilidade Gerencial. O estudo descritivo foi desenvolvido por meio de questionário aplicado aos professores da área gerencial dos programas de pós-graduação em ciências contábeis do Brasil. Os resultados da pesquisa mostram que a função atual da Contabilidade Gerencial está focalizada no uso de recursos e na criação de valor e que a tendência da Contabilidade Gerencial na opinião dos respondentes continuará sendo na criação de valor. Preveem que a Contabilidade Gerencial utilizará sistemas com dados monetários e não monetários, métodos de mensuração/avaliação e medidas de desempenho, filosofias e modelos de gestão. Como artefatos de Contabilidade Gerencial que serão mais utilizados apontaram: custeio variável, preço de transferência, retorno sobre o investimento e orçamento.

\section{METODOLOGIA}

\subsection{Classificação dos artefatos de Contabilidade Gerencial}

Para responder à questão de pesquisa e atender os objetivos estabelecidos, os artefatos foram classificados entre modernos e tradicionais, considerando sua adequação aos estágios evolutivos da Contabilidade Gerencial conforme estudo do IFAC (1998), como apresentado na Tabela 1. Foram consideradas, também, a segregação apresentada por Sulaiman et al. (2004), a distribuição dos artefatos proposta por Soutes e Zen (2005), bem como as considerações sobre artefatos de Contabilidade Gerencial apresentadas nos diversos estudos citados no tópico 2.

\section{Tabela 1}

Artefatos classificados por estágios

\begin{tabular}{l|c|c}
\hline Artefatos & $\begin{array}{c}\mathbf{1}^{\mathbf{o}} \mathbf{-} \mathbf{2}^{\mathbf{o}} . \\
\text { Estágios }\end{array}$ & $\begin{array}{c}\mathbf{3}^{\mathbf{0}} \cdot \mathbf{- \mathbf { 4 } ^ { \mathbf { } }} \\
\text { Estágios }\end{array}$ \\
\hline Custeio por absorção & $\mathrm{x}$ & \\
\hline Custeio variável & $\mathrm{x}$ & \\
\hline Custeio padrão & $\mathrm{x}$ & \\
\hline \multicolumn{2}{|c}{ continua }
\end{tabular}

\begin{tabular}{l|c|c} 
Continuação & $\begin{array}{c}\mathbf{1}^{\mathbf{o}} \mathbf{- 2} \mathbf{0} \\
\text { Estágios }\end{array}$ & $\begin{array}{c}\mathbf{3}^{\mathbf{o}} \mathbf{- \mathbf { 4 } ^ { \mathbf { } }} \\
\text { Estágios }\end{array}$ \\
\hline Preço de transferência & $\mathrm{x}$ & \\
\hline Moeda Constante & $\mathrm{x}$ & \\
\hline Valor Presente & $\mathrm{x}$ & \\
\hline Orçamento & $\mathrm{x}$ & \\
\hline Custeio baseado em Atividades & & $\mathrm{x}$ \\
\hline Custeio Meta (Target Costing) & & $\mathrm{x}$ \\
\hline Benchmarking & & $\mathrm{x}$ \\
\hline Kaizen & & $\mathrm{x}$ \\
\hline Just in Time (JIT) & & $\mathrm{x}$ \\
\hline Teoria das Restrições & & $\mathrm{x}$ \\
\hline Custo Financeiro dos Estoques & & $\mathrm{x}$ \\
\hline Economic Value Added (EVA) & & $\mathrm{x}$ \\
\hline Simulações & & $\mathrm{x}$ \\
\hline Balanced Scorecard (BSC) & & $\mathrm{x}$ \\
\hline
\end{tabular}

\subsection{Objetivos, amostra e coleta de dados}

Como mencionado anteriormente, esta pesquisa tem dois objetivos fundamentais. $\mathrm{O}$ primeiro diz respeito a identificar se as grandes empresas brasileiras usam artefatos mo- 
dernos de Contabilidade Gerencial e o segundo é examinar se as companhias que se destacam pela qualidade das informações geradas aos usuários externos, também, se destacam no atendimento informativo de seus usuários internos, mediante a adoção de artefatos modernos de Contabilidade Gerencial.

Para atender o segundo objetivo foram estabelecidas as seguintes hipóteses:

$\mathrm{H}_{1}$ : Indicadores monetários e não monetários selecionados das empresas indicadas são significativamente maiores do que os mesmos indicadores das companhias do outro grupo. Para cada indicador (empregados, lucro líquido, patrimônio líquido, ativos, passivos, receitas, variação anual do lucro líquido, variação anual do patrimônio líquido, retorno sobre ativo e retorno sobre patrimônio líquido) foi empregado o teste-t para verificar essa hipótese com base no nível alfa de 0,5.

$\mathrm{H}_{2}$ : As companhias indicadas apresentam de forma significativa maior uso de cada instrumento de Contabilidade Gerencial quando comparadas com as empresas do outro grupo. Para checar essa hipótese foi empregado o teste-t unidirecional (alfa $0,5)$ para cada um dos vinte e quatro quesitos do instrumento de coleta de dados.

$\mathrm{H}_{3}$ : As companhias indicadas apresentam de forma significativa maior uso de artefatos tradicionais de Contabilidade Gerencial quando comparadas com as empresas do outro grupo. Para checar essa hipótese foi utilizado um teste-t unidirecional (alfa 0,5$)$ para cada um dos dez quesitos relacionados a artefatos tradicionais constantes do instrumento de coleta de dados.

$\mathrm{H}_{4}$ : As companhias indicadas apresentam de forma significativa maior uso de artefatos modernos de Contabilidade Gerencial quando comparadas com as empresas do outro grupo. Para checar essa hipótese foi utilizado teste-t unidirecional (alfa 0,5$)$ para cada um dos quatorze quesitos relacionados a artefatos tradicionais constantes do instrumento de coleta de dados.

O questionário utilizado para a pesquisa apresentou 24 questões sobre a utilização de artefatos da Contabilidade Gerencial, sendo que 14 eram referentes à utilização de artefatos modernos. Foi solicitado ao respondente que assinalasse o grau de concordância com a utilização de cada artefato em sua empresa, consideradas as seguintes opções: "concordo totalmente", "concordo parcialmente", "não concordo nem discordo", "discordo parcialmente" e "discordo totalmente".

O questionário foi encaminhado para dois grupos de empresas no período de novembro de 2005 a fevereiro de 2006 . Os grupos foram denominados de "empresas indicadas" e "demais empresas", conforme segue:

- Empresas Indicadas: Correspondem a um conjunto de 40 empresas indicadas ao Prêmio ANEFAC-FIPECAFI-SERASA (Troféu Transparência).

- Demais Empresas: Correspondem a um conjunto de empresas listadas entre as 500 maiores empresas constantes do caderno Melhores e Maiores da Revista Exame de julho/2005.

Inicialmente, a população foi composta por 544 empresas e no final a população, após depurações, foi formada por $502 \mathrm{em}$ presas. Obteve-se resposta de 90 empresas, sendo 29 de empresas indicadas e 61 de demais empresas. A distribuição da amostra final, considerando o setor econômico, é apresentada na Tabela 2. 
Tabela 2 Composição da amostra quanto ao setor econômico

\begin{tabular}{l|c}
\hline Setor Econômico & Quantidade \\
\hline Alimentos, bebidas e fumo & 12 \\
\hline Automotivo e peças & 4 \\
\hline Atacado e comércio exterior & 8 \\
\hline Comércio varejista & 2 \\
\hline Construção & 4 \\
\hline Eletroeletrônico & 2 \\
\hline Farmacêutico, higiene e cosméticos & 4 \\
\hline Limpeza & 1 \\
\hline Material de construção & 4 \\
\hline Mecânica & 1 \\
\hline Mineração & 3 \\
\hline Papel e celulose & 3 \\
\hline Química e petroquímica & 8 \\
\hline Serviços de transporte & 5 \\
\hline Serviços diversos & $\mathbf{9 0}$ \\
\hline Serviços públicos & 4 \\
\hline Siderurgia e metalurgia & 6 \\
\hline Comunicações & 2 \\
\hline Não identificado & 4 \\
\hline Total & 2 \\
\hline
\end{tabular}

\section{RESULTADOS OBTIDOS}

\subsection{Questões preliminares}

Preliminarmente às questões fundamentais do estudo, foram efetuadas indagações a respeito da existência de um departamento específico responsável pela Contabilidade Gerencial na empresa e sobre a utilização de serviços de consultoria externa.

\subsubsection{A existência de um departamento responsável}

Comprovou-se que, praticamente, todas as empresas da amostra possuem um departamento ou setor que cuida especificamente das informações da Contabilidade Gerencial e a geração de informações gerenciais é uma das principais funções dessa área. Esse resultado é compatível com os obtidos nas pesquisas de Adelegan (2006), Soutes e Zen (2005) e Garg et al. (2003).

\subsubsection{A utilização de serviços de consultoria externa}

O estudo de caráter exploratório realizado por Oyadomari et al. (2008) evidenciou a importância do trabalho de consultoria externa na introdução de instrumentos de Contabilidade Gerencial nas empresas. Segundo esse estudo, as empresas buscam esses profissionais tanto por conta de sua experiência na realização de trabalhos similares e também porque os consultores legitimam as decisões tomadas pelas empresas.

Foi indagado sobre a utilização de consultoria externa para ajudar a implementação de artefatos de Contabilidade Gerencial. Somente 8 (oito) informaram que não utilizam esses serviços, sendo os resultados obtidos apresentados na Tabela 3. 
Tabela 3 Distribuição dos serviços de consultoria externa

\begin{tabular}{l|c}
\hline & Total \\
\hline Não & 8 \\
\hline Sim, em gestão da qualidade total. & 53 \\
\hline Sim, em implantação de sistemas de custos. & 31 \\
\hline $\begin{array}{l}\text { Sim, em implantação de sistema de custeio } \\
\text { ABC. }\end{array}$ & 11 \\
\hline Sim, em implantação de sistema de orçamento. & 35 \\
\hline $\begin{array}{l}\text { Sim, em implantação de processo de planeja- } \\
\text { mento estratégico. }\end{array}$ & 48 \\
\hline Sim, em implantação de EVA. & 16 \\
\hline $\begin{array}{l}\text { Sim, em implantação de Custeio Meta (Target } \\
\text { Costing). }\end{array}$ & 2 \\
\hline Sim, em implantação de Just-in-Time. & 3 \\
\hline \multicolumn{1}{l}{ continua }
\end{tabular}

continuação

\begin{tabular}{l|c}
\hline & Total \\
\hline $\begin{array}{l}\text { Sim, em implantação de gestão baseada em } \\
\text { valor (VBM). }\end{array}$ & 9 \\
\hline Sim, em implantação de Balanced Scorecard. & 31 \\
\hline Sim, em implantação de Benchmarking. & 12 \\
\hline Sim, em implantação de Teoria das Restrições. & 4 \\
\hline Sim, em implantação de modelo GECON. & 7 \\
\hline Sim, em implantação de gestão de Logística. & 26 \\
\hline Sim, outros. & 19 \\
\hline
\end{tabular}

\subsection{Artefatos da Contabilidade Gerencial utilizados}

A distribuição de respostas relativas à utilização de artefatos tradicionais e artefatos modernos é apresentada na Tabela 4.

Tabela 4 Distribuição dos artefatos de Contabilidade Gerencial

\begin{tabular}{|c|c|c|c|c|c|c|c|c|c|c|}
\hline Artefatos & CT & СР & NN & DP & DT & CT & $\mathbf{C P}$ & NN & DP & DT \\
\hline Custeio por absorção & 45 & 9 & 10 & 5 & 21 & $50 \%$ & $10 \%$ & $11 \%$ & $6 \%$ & $23 \%$ \\
\hline Custeio variável - questão 1 & 20 & 14 & 18 & 7 & 31 & $22 \%$ & $16 \%$ & $20 \%$ & $8 \%$ & $34 \%$ \\
\hline Custeio variável - questão 2 & 56 & 18 & 6 & 6 & 4 & $62 \%$ & $20 \%$ & $7 \%$ & $7 \%$ & $4 \%$ \\
\hline Custeio padrão - questão 1 & 22 & 15 & 12 & 7 & 34 & $24 \%$ & $17 \%$ & $13 \%$ & $8 \%$ & $38 \%$ \\
\hline Custeio padrão - questão 2 & 25 & 24 & 9 & 2 & 30 & $28 \%$ & $27 \%$ & $10 \%$ & $2 \%$ & $33 \%$ \\
\hline Preço de transferência - questão 1 & 24 & 8 & 18 & 4 & 36 & $27 \%$ & $9 \%$ & $20 \%$ & $4 \%$ & $40 \%$ \\
\hline Preço de transferência - questão 2 & 16 & 13 & 18 & 5 & 38 & $18 \%$ & $14 \%$ & $20 \%$ & $6 \%$ & $42 \%$ \\
\hline Moeda Constante & 25 & 14 & 7 & 4 & 40 & $28 \%$ & $16 \%$ & $8 \%$ & $4 \%$ & $44 \%$ \\
\hline Valor Presente & 20 & 27 & 19 & 4 & 20 & $22 \%$ & $30 \%$ & $21 \%$ & $4 \%$ & $22 \%$ \\
\hline Orçamento & 48 & 33 & 4 & 4 & 1 & $53 \%$ & $37 \%$ & $4 \%$ & $4 \%$ & $1 \%$ \\
\hline Custeio baseado em Atividades & 7 & 20 & 11 & 11 & 41 & $8 \%$ & $22 \%$ & $12 \%$ & $12 \%$ & $46 \%$ \\
\hline Custeio Meta - questão 1 & 4 & 26 & 25 & 7 & 28 & $4 \%$ & $29 \%$ & $28 \%$ & $8 \%$ & $31 \%$ \\
\hline Custeio Meta - questão 2 & 19 & 26 & 19 & 13 & 13 & $21 \%$ & $29 \%$ & $21 \%$ & $14 \%$ & $14 \%$ \\
\hline Benchmarking - questão 1 & 42 & 32 & 10 & 1 & 5 & $47 \%$ & $36 \%$ & $11 \%$ & $1 \%$ & $6 \%$ \\
\hline Benchmarking - questão 2 & 51 & 25 & 4 & 8 & 2 & $57 \%$ & $28 \%$ & $4 \%$ & $9 \%$ & $2 \%$ \\
\hline Kaizen & 14 & 15 & 19 & 7 & 35 & $16 \%$ & $17 \%$ & $21 \%$ & $8 \%$ & $39 \%$ \\
\hline Just-in-Time (JIT) & 12 & 16 & 17 & 8 & 37 & $13 \%$ & $18 \%$ & $19 \%$ & $9 \%$ & $41 \%$ \\
\hline Teoria das Restrições & 16 & 31 & 18 & 5 & 20 & $18 \%$ & $34 \%$ & $20 \%$ & $6 \%$ & $22 \%$ \\
\hline Custo Financeiro dos Estoques & 27 & 23 & 9 & 4 & 27 & $30 \%$ & $26 \%$ & $10 \%$ & $4 \%$ & $30 \%$ \\
\hline Economic Value Added (EVA) & 33 & 12 & 12 & 5 & 28 & $37 \%$ & $13 \%$ & $13 \%$ & $6 \%$ & $31 \%$ \\
\hline Simulações - questão 1 & 60 & 19 & 7 & 3 & 1 & $67 \%$ & $21 \%$ & $8 \%$ & $3 \%$ & $1 \%$ \\
\hline Simulações - questão 2 & 34 & 18 & 14 & 10 & 14 & $38 \%$ & $20 \%$ & $16 \%$ & $11 \%$ & $16 \%$ \\
\hline Balanced Scorecard & 24 & 17 & 10 & 5 & 34 & $27 \%$ & $19 \%$ & $11 \%$ & $6 \%$ & $38 \%$ \\
\hline
\end{tabular}

Legenda: CT - Concorda Totalmente, CP - Concorda Parcialmente, NN - Não concorda nem discorda, DT - Discorda Totalmente, DP - Discorda Parcialmente.

Obs.: Os artefatos considerados "modernos" estão sombreados. 


\subsubsection{Artefatos tradicionais}

\section{Custeio por absorção}

Indagadas sobre a utilização do método de custeio, 54 empresas (60\%) afirmaram que, para efeito gerencial, o custo dos produ- tos em suas empresas é calculado com base no método de custeio por absorção. A Tabela 5 apresenta o estrato das respostas obtidas quanto à concordância da utilização desse artefato para fins gerenciais.

Tabela 5 Respostas relativas à utilização do custeio por absorção para fins gerenciais

\begin{tabular}{l|c|c|c|c|c|c}
\hline & \multicolumn{2}{|c|}{ Quantidade de respondentes } & \multicolumn{3}{c}{ Participação \% } \\
\hline & $\begin{array}{c}\text { Empresas } \\
\text { Indicadas }\end{array}$ & $\begin{array}{c}\text { Demais } \\
\text { empresas }\end{array}$ & Total & $\begin{array}{c}\text { Empresas } \\
\text { Indicadas }\end{array}$ & $\begin{array}{c}\text { Demais } \\
\text { empresas }\end{array}$ & Total \\
\hline Concorda totalmente & 17 & 28 & 45 & $59 \%$ & $46 \%$ & $50 \%$ \\
\hline Concorda parcialmente & 3 & 6 & 9 & $10 \%$ & $10 \%$ & $10 \%$ \\
\hline Não concorda nem discorda & 2 & 8 & 10 & $7 \%$ & $13 \%$ & $11 \%$ \\
\hline Discorda parcialmente & 1 & 4 & 5 & $3 \%$ & $7 \%$ & $6 \%$ \\
\hline Discorda totalmente & 6 & 15 & 21 & $21 \%$ & $25 \%$ & $23 \%$ \\
\hline Total & 29 & 61 & 90 & $100 \%$ & $100 \%$ & $100 \%$ \\
\hline
\end{tabular}

Os resultados podem ser considerados próximos ao obtido por Haldma e Lääts (2002), os quais observaram que $54,8 \%$ da amostra de empresas de manufatura da Estônia utilizam o custeio por absorção e ao de Soutes e Zen (2005), 61\%. O estudo desenvolvido por Szychta (2006), em amostra de empresas polonesas, indica um nível de utilização de $90 \%$ em 1999 e de $71,1 \%$ em 2005. Hughes e Gjerde (2003) informaram que, para amostra de empresas dos Estados Unidos, o percentual de utilização do custeio por absorção para fins gerenciais foi de 35\%.

\section{Custeio variável e margem de contri-} buição

O questionário continha duas questões para avaliar a utilização do método de custeio variável: (i) "para efeito gerencial, o custo dos produtos é calculado com base no método de custeio variável” e (ii) "a empresa utiliza o conceito de margem de contribuição (receita menos custos e despesas variáveis dos produtos)". As respostas são apresentadas nas Tabelas 6 e 7.

Tabela 6 Respostas relativas ao cálculo do custo do produto pelo custeio variável

\begin{tabular}{l|c|c|c|c|c|c}
\hline & \multicolumn{2}{|c|}{ Quantidade de respondentes } & \multicolumn{3}{c}{ Participação \% } \\
\hline & $\begin{array}{c}\text { Empresas } \\
\text { Indicadas }\end{array}$ & $\begin{array}{c}\text { Demais } \\
\text { empresas }\end{array}$ & Total & $\begin{array}{c}\text { Empresas } \\
\text { Indicadas }\end{array}$ & $\begin{array}{c}\text { Demais } \\
\text { empresas }\end{array}$ & Total \\
\hline Concorda totalmente & 5 & 15 & 20 & $17 \%$ & $25 \%$ & $22 \%$ \\
\hline Concorda parcialmente & 4 & 10 & 14 & $14 \%$ & $16 \%$ & $16 \%$ \\
\hline Não concorda nem discorda & 6 & 12 & 18 & $21 \%$ & $20 \%$ & $20 \%$ \\
\hline Discorda parcialmente & 2 & 5 & 7 & $7 \%$ & $8 \%$ & $8 \%$ \\
\hline Discorda totalmente & 12 & 19 & 31 & $41 \%$ & $31 \%$ & $34 \%$ \\
\hline Total & 29 & 61 & 90 & $100 \%$ & $100 \%$ & $100 \%$ \\
\hline
\end{tabular}


Tabela 7 Respostas relativas à utilização do conceito de margem de contribuição

\begin{tabular}{l|c|c|c|c|c|c}
\hline & \multicolumn{2}{|c|}{ Quantidade de respondentes } & \multicolumn{3}{c}{ Participação \% } \\
\hline & $\begin{array}{c}\text { Empresas } \\
\text { Indicadas }\end{array}$ & $\begin{array}{c}\text { Demais } \\
\text { empresas }\end{array}$ & Total & $\begin{array}{c}\text { Empresas } \\
\text { Indicadas }\end{array}$ & $\begin{array}{c}\text { Demais } \\
\text { empresas }\end{array}$ & Total \\
\hline Concorda totalmente & 15 & 41 & 56 & $52 \%$ & $67 \%$ & $62 \%$ \\
\hline Concorda parcialmente & 6 & 12 & 18 & $21 \%$ & $20 \%$ & $20 \%$ \\
\hline Não concorda nem discorda & 2 & 4 & 6 & $7 \%$ & $7 \%$ & $7 \%$ \\
\hline Discorda parcialmente & 4 & 2 & 6 & $14 \%$ & $3 \%$ & $7 \%$ \\
\hline Discorda totalmente & 2 & 2 & 4 & $7 \%$ & $3 \%$ & $4 \%$ \\
\hline Total & 29 & 61 & 90 & $100 \%$ & $100 \%$ & $100 \%$ \\
\hline
\end{tabular}

Os resultados evidenciam que, em menos da metade das empresas respondentes (38\%), o custeio variável é utilizado gerencialmente, porém o que surpreende é o número de respondentes que afirmaram utilizar o conceito de margem de contribuição ( $82 \%$ dos respondentes), o que indica falta de conhecimento desse conceito pelos respondentes.

Os resultados das pesquisas em âmbito mundial são discrepantes: Haldma e Lääts (2002) afirmaram que $38,7 \%$ da amostra de empresas de manufatura da Estônia utilizam o custeio variável. O estudo de Szychta (2006), em amostra de empresas polonesas, indica que a utilização do método de custeio variável vem crescendo naquele país, subindo de 16,7\% em 1999 para $32,2 \%$ em 2005. Hughes e Gjerde (2003) retrataram que apenas $22 \%$ das empresas da amostra estudada nos Estados Unidos utilizam o Custeio Variável, e Soutes e Zen
(2005) mostraram que $48 \%$ do grupo de empresas brasileiras estudadas o utilizam. Em amostra de empresas pesquisada na Nigéria, Adelegan (2006) constatou que $40 \%$ das empresas estudadas utilizam esse método de custeio. Apesar das disparidades entre os resultados encontrados nas diversas pesquisas, todas indicam que essa prática, apesar de considerada tradicional, é utilizada por menos de $50 \%$ das empresas pesquisadas.

\section{Custeio padrão}

Com o objetivo de verificar a utilização dessa prática, foram efetuadas duas questões: (i) "a empresa utiliza o custeio padrão como instrumento de controle de custos" e (ii) "os gestores são cobrados pelas variações registradas entre o custo padrão e o custo real obtido". As Tabelas 8 e 9 apresentam o estrato detalhado das respostas obtidas para as duas questões.

Tabela 8 Respostas relativas ao emprego do custo padrão como instrumento de controle de custos

\begin{tabular}{l|c|c|c|c|c|c}
\hline & \multicolumn{2}{|c|}{ Quantidade de respondentes } & \multicolumn{3}{c}{ Participação \% } \\
\hline & $\begin{array}{c}\text { Empresas } \\
\text { Indicadas }\end{array}$ & $\begin{array}{c}\text { Demais } \\
\text { empresas }\end{array}$ & Total & $\begin{array}{c}\text { Empresas } \\
\text { Indicadas }\end{array}$ & $\begin{array}{c}\text { Demais } \\
\text { empresas }\end{array}$ & Total \\
\hline Concorda totalmente & 6 & 16 & 22 & $21 \%$ & $26 \%$ & $24 \%$ \\
\hline Concorda parcialmente & 6 & 9 & 15 & $21 \%$ & $15 \%$ & $17 \%$ \\
\hline Não concorda nem discorda & 3 & 9 & 12 & $10 \%$ & $15 \%$ & $13 \%$ \\
\hline Discorda parcialmente & 3 & 4 & 7 & $10 \%$ & $7 \%$ & $8 \%$ \\
\hline Discorda totalmente & 11 & 23 & 34 & $38 \%$ & $38 \%$ & $38 \%$ \\
\hline Total & 29 & 61 & 90 & $100 \%$ & $100 \%$ & $100 \%$ \\
\hline
\end{tabular}


Tabela 9 Respostas relativas ao emprego das variações de custos para avaliar desempenho de gestores

\begin{tabular}{l|c|c|c|c|c|c}
\hline & \multicolumn{2}{|c|}{ Quantidade de respondentes } & \multicolumn{3}{c}{ Participação \% } \\
\hline & $\begin{array}{c}\text { Empresas } \\
\text { Indicadas }\end{array}$ & $\begin{array}{c}\text { Demais } \\
\text { empresas }\end{array}$ & Total & $\begin{array}{c}\text { Empresas } \\
\text { Indicadas }\end{array}$ & $\begin{array}{c}\text { Demais } \\
\text { empresas }\end{array}$ & Total \\
\hline Concorda totalmente & 10 & 15 & 25 & $34 \%$ & $25 \%$ & $28 \%$ \\
\hline Concorda parcialmente & 5 & 19 & 24 & $17 \%$ & $31 \%$ & $27 \%$ \\
\hline Não concorda nem discorda & 1 & 8 & 9 & $3 \%$ & $13 \%$ & $10 \%$ \\
\hline Discorda parcialmente & 1 & 1 & 2 & $3 \%$ & $2 \%$ & $2 \%$ \\
\hline Discorda totalmente & 12 & 18 & 30 & $41 \%$ & $30 \%$ & $33 \%$ \\
\hline Total & 29 & 61 & 90 & $100 \%$ & $100 \%$ & $100 \%$ \\
\hline
\end{tabular}

No grupo das indicadas, $21 \%$ dos respondentes afirmaram utilizar o custeio padrão, porém, $34 \%$ afirmaram que os gestores são cobrados pelas variações registradas entre o custo padrão e o custo real. É muito provável que a cobrança deva ocorrer não necessariamente pelo custo padrão, mas pelo custo do orçamento. No grupo das demais empresas, $26 \%$ afirmaram que utilizam o custeio padrão e $25 \%$ que os gestores são cobrados pelas variações percebidas.

Os resultados de outras pesquisas são bastante variáveis. No caso do estudo de $\mathrm{Su}$ laiman, Ahmad e Alwi (2004), os índices de adoção do custeio padrão nos países da Ásia estudados podem ser considerados altos. $\mathrm{Na}$ pesquisa de Soutes e Zen (2005), verifica-se utilização por $31 \%$ das empresas da amostra e no caso do estudo de Adelegan (2006), entre empresas de manufatura da Nigéria, o índice de adoção pode ser considerado muito baixo (4\% das empresas da amostra). O estudo de Szychta (2006) com empresas polonesas indica a utilização desse conceito por $23,2 \%$ das empresas da amostra estudada. Os resultados da pesquisa de Frezatti (2005) indicam um nível de aderência entre a prática e a teoria em torno de $32 \%$.

\section{Preço de transferência}

Para verificar qual conceito de preço de transferência as empresas da amostra têm utilizado, foram feitas duas perguntas: (i) "para efeitos gerenciais, a empresa utiliza o preço de transferência baseado em custos" e (ii) "para efeitos gerenciais, a empresa utiliza o preço de transferência baseado em preços de mercado". As respostas estão apresentadas nas Tabelas 10 e 11 .

Tabela 10 Respostas relativas à utilização do preço de transferência baseado em custos

\begin{tabular}{l|c|c|c|c|c|c}
\hline & \multicolumn{2}{|c|}{ Quantidade de respondentes } & \multicolumn{3}{c}{ Participação \% } \\
\hline & $\begin{array}{c}\text { Empresas } \\
\text { Indicadas }\end{array}$ & $\begin{array}{c}\text { Demais } \\
\text { empresas }\end{array}$ & Total & $\begin{array}{c}\text { Empresas } \\
\text { Indicadas }\end{array}$ & $\begin{array}{c}\text { Demais } \\
\text { empresas }\end{array}$ & Total \\
\hline Concorda totalmente & 7 & 17 & 24 & $24 \%$ & $28 \%$ & $27 \%$ \\
\hline Concorda parcialmente & 1 & 7 & 8 & $3 \%$ & $11 \%$ & $9 \%$ \\
\hline Não concorda nem discorda & 8 & 10 & 18 & $28 \%$ & $16 \%$ & $20 \%$ \\
\hline Discorda parcialmente & 3 & 1 & 4 & $10 \%$ & $2 \%$ & $4 \%$ \\
\hline Discorda totalmente & 10 & 26 & 36 & $34 \%$ & $43 \%$ & $40 \%$ \\
\hline Total & 29 & 61 & 90 & $100 \%$ & $100 \%$ & $100 \%$ \\
\hline
\end{tabular}


Tabela 11 Respostas relativas à utilização do preço de transferência baseado em preços de mercado

\begin{tabular}{l|c|c|c|c|c|c}
\hline & \multicolumn{2}{|c|}{ Quantidade de respondentes } & \multicolumn{3}{c}{ Participação \% } \\
\hline & $\begin{array}{c}\text { Empresas } \\
\text { Indicadas }\end{array}$ & $\begin{array}{c}\text { Demais } \\
\text { empresas }\end{array}$ & Total & $\begin{array}{c}\text { Empresas } \\
\text { Indicadas }\end{array}$ & $\begin{array}{c}\text { Demais } \\
\text { empresas }\end{array}$ & Total \\
\hline Concorda totalmente & 8 & 8 & 16 & $28 \%$ & $13 \%$ & $18 \%$ \\
\hline Concorda parcialmente & 3 & 10 & 13 & $10 \%$ & $16 \%$ & $14 \%$ \\
\hline Não concorda nem discorda & 9 & 9 & 18 & $31 \%$ & $15 \%$ & $20 \%$ \\
\hline Discorda parcialmente & 2 & 3 & 5 & $7 \%$ & $5 \%$ & $6 \%$ \\
\hline Discorda totalmente & 7 & 31 & 38 & $24 \%$ & $51 \%$ & $42 \%$ \\
\hline Total & 29 & 61 & 90 & $100 \%$ & $100 \%$ & $100 \%$ \\
\hline
\end{tabular}

Constatou-se que as empresas da amostra utilizam tanto o preço baseado em custos (36\%), quanto o preço baseado em parâmetros de mercado (32\%). Não foram encontradas outras pesquisas que apresentem índices de utilização desse artefato.

\section{Moeda constante e valor presente}

A utilização dos conceitos de moeda cons- tante e valor presente no âmbito das empresas pesquisadas foi averiguada a partir das indagações: (i) "são elaborados e analisados relatórios gerenciais em moeda constante" e (ii) "a empresa trabalha com conceito de valor presente para custos e despesas". As Tabelas 12 e 13 apresentam os resultados estratificados dessas duas questões.

Tabela 12 Respostas relativas ao emprego do conceito de moeda constante

\begin{tabular}{l|c|c|c|c|c|c}
\hline & \multicolumn{2}{|c|}{ Quantidade de respondentes } & \multicolumn{3}{c}{ Participação \% } \\
\hline & $\begin{array}{c}\text { Empresas } \\
\text { Indicadas }\end{array}$ & $\begin{array}{c}\text { Demais } \\
\text { empresas }\end{array}$ & Total & $\begin{array}{c}\text { Empresas } \\
\text { Indicadas }\end{array}$ & $\begin{array}{c}\text { Demais } \\
\text { empresas }\end{array}$ & Total \\
\hline Concorda totalmente & 11 & 14 & 25 & $38 \%$ & $23 \%$ & $28 \%$ \\
\hline Concorda parcialmente & 5 & 9 & 14 & $17 \%$ & $15 \%$ & $16 \%$ \\
\hline Não concorda nem discorda & 1 & 6 & 7 & $3 \%$ & $10 \%$ & $8 \%$ \\
\hline Discorda parcialmente & 2 & 2 & 4 & $7 \%$ & $3 \%$ & $4 \%$ \\
\hline Discorda totalmente & 10 & 30 & 40 & $34 \%$ & $49 \%$ & $44 \%$ \\
\hline Total & 29 & 61 & 90 & $100 \%$ & $100 \%$ & $100 \%$ \\
\hline
\end{tabular}

Tabela 13 Respostas relativas ao emprego do conceito de valor presente

\begin{tabular}{l|c|c|c|c|c|c}
\hline & \multicolumn{2}{|c|}{ Quantidade de respondentes } & \multicolumn{3}{c}{ Participação \% } \\
\hline & $\begin{array}{c}\text { Empresas } \\
\text { Indicadas }\end{array}$ & $\begin{array}{c}\text { Demais } \\
\text { empresas }\end{array}$ & Total & $\begin{array}{c}\text { Empresas } \\
\text { Indicadas }\end{array}$ & $\begin{array}{c}\text { Demais } \\
\text { empresas }\end{array}$ & Total \\
\hline Concorda totalmente & 5 & 15 & 20 & $17 \%$ & $25 \%$ & $22 \%$ \\
\hline Concorda parcialmente & 12 & 15 & 27 & $41 \%$ & $25 \%$ & $30 \%$ \\
\hline Não concorda nem discorda & 6 & 13 & 19 & $21 \%$ & $21 \%$ & $21 \%$ \\
\hline Discorda parcialmente & 2 & 2 & 4 & $7 \%$ & $3 \%$ & $4 \%$ \\
\hline Discorda totalmente & 4 & 16 & 20 & $14 \%$ & $26 \%$ & $22 \%$ \\
\hline Total & 29 & 61 & 90 & $100 \%$ & $100 \%$ & $100 \%$ \\
\hline
\end{tabular}


Os resultados evidenciaram que $44 \%$ dos respondentes geram relatórios em moeda constante e $52 \%$ trabalham com conceito de valor presente.

\section{Orçamento}

Os respondentes indicaram o grau de concordância com a afirmação "os gestores utilizam o orçamento como base para tomada de decisão" e os resultados obtidos evidenciam que $90 \%$ das empresas da amostra utilizam o orçamento, conforme exposto na Tabela 14.

Tabela 14 Respostas relativas ao emprego do orçamento como instrumento de tomada de decisão

\begin{tabular}{l|c|c|c|c|c|c}
\hline & \multicolumn{2}{|c|}{ Quantidade de respondentes } & \multicolumn{3}{c}{ Participação \% } \\
\hline & $\begin{array}{c}\text { Empresas } \\
\text { Indicadas }\end{array}$ & $\begin{array}{c}\text { Demais } \\
\text { empresas }\end{array}$ & Total & $\begin{array}{c}\text { Empresas } \\
\text { Indicadas }\end{array}$ & $\begin{array}{c}\text { Demais } \\
\text { empresas }\end{array}$ & Total \\
\hline Concorda totalmente & 13 & 35 & 48 & $45 \%$ & $57 \%$ & $53 \%$ \\
\hline Concorda parcialmente & 13 & 20 & 33 & $45 \%$ & $33 \%$ & $37 \%$ \\
\hline Não concorda nem discorda & 0 & 4 & 4 & $0 \%$ & $7 \%$ & $4 \%$ \\
\hline Discorda parcialmente & 2 & 2 & 4 & $7 \%$ & $3 \%$ & $4 \%$ \\
\hline Discorda totalmente & 1 & 0 & 1 & $3 \%$ & $0 \%$ & $1 \%$ \\
\hline Total & 29 & 61 & 90 & $100 \%$ & $100 \%$ & $100 \%$ \\
\hline
\end{tabular}

Esses resultados são consistentes com resultados de estudos anteriores ( $\mathrm{CHE}$ NHALL; LANGFIELD-SMITH, 1998c; SULAIMAN; AHMAD; ALWI, 2004). O estudo de Soutes e Zen (2005) demonstrou que $90 \%$ dos seus respondentes fazem uso do orçamento anual e $43 \%$ do orçamento de capital.

\subsubsection{Artefatos modernos}

\section{Custeio baseado em atividades (ABC)}

Quando questionados se "a empresa utiliza o custeio baseado em atividades (ABC)", 46\% afirmaram "discordar totalmente" contra $8 \%$ que afirmaram "concordar totalmente" com a utilização dessa prática. A Tabela 15 apresenta o detalhamento dos resultados obtidos.

Tabela 15 Respostas relativas à utilização do sistema de custeio baseado em atividades (ABC)

\begin{tabular}{l|c|c|c|c|c|c}
\hline & \multicolumn{2}{|c|}{ Quantidade de respondentes } & \multicolumn{3}{c}{ Participação \% } \\
\hline & $\begin{array}{c}\text { Empresas } \\
\text { Indicadas }\end{array}$ & $\begin{array}{c}\text { Demais } \\
\text { empresas }\end{array}$ & Total & $\begin{array}{c}\text { Empresas } \\
\text { Indicadas }\end{array}$ & $\begin{array}{c}\text { Demais } \\
\text { empresas }\end{array}$ & Total \\
\hline Concorda totalmente & 0 & 7 & 7 & $0 \%$ & $11 \%$ & $8 \%$ \\
\hline Concorda parcialmente & 5 & 15 & 20 & $17 \%$ & $25 \%$ & $22 \%$ \\
\hline Não concorda nem discorda & 5 & 6 & 11 & $17 \%$ & $10 \%$ & $12 \%$ \\
\hline Discorda parcialmente & 4 & 7 & 11 & $14 \%$ & $11 \%$ & $12 \%$ \\
\hline Discorda totalmente & 15 & 26 & 41 & $52 \%$ & $43 \%$ & $46 \%$ \\
\hline Total & 29 & 61 & 90 & $100 \%$ & $100 \%$ & $100 \%$ \\
\hline
\end{tabular}

Os resultados obtidos são similares aos de pesquisas realizadas no exterior que indicam a baixa utilização desse artefato. Evans e Ashworth (1996) mencionam que somente $21 \%$ das companhias têm desenvolvido alguma atividade para a introdução do siste- ma $\mathrm{ABC}$ e, dentre essas, apenas $28 \%$ têm implantado efetivamente o sistema. O estudo de Innes, Mitchell e Sinclair (2000) reporta que a utilização desse sistema permaneceu estável no período de 1994 a 1999, com taxas de utilização, respectivamente, de $21 \%$ 
e 17,5\%. Haldma e Lääts (2002) observam que apenas $7 \%$ da amostra de empresas de manufatura da Estônia utilizam o custeio baseado em atividades. Szychta (2006), em amostra de empresas polonesas, relata a utilização por $10 \%$ das empresas da amostra. Chenhall e Langfield-Smith (1998b) o classificaram como sendo de baixa adoção e Hughes e Gjerde (2003) constataram que apenas $8 \%$ da amostra de empresas dos Estados Unidos utilizam esse artefato. Esse mesmo percentual (8\%) foi o resultado obtido por Soutes e Zen (2005) na sua amostra de empresas brasileiras estudadas. Adelegan (2006) relatou que $22 \%$ do conjunto de empresas de manufatura da Nigéria o utilizam. Já Cagwin e Bouwman (2002) obtiveram um resultado de utilização de $23 \%$ na amostra de empresas auditadas pelo Institute Internal Auditors (IIA) dos Estados Unidos da América. Os resultados da pesquisa de Frezatti (2005) indicam um nível de aderência entre a prática e a teoria em torno de $15 \%$.

\section{Custeio meta (Target Costing)}

A utilização do custeio meta foi investigada por meio de duas questões: (i) "a empresa utiliza o conceito de custeio meta" e (ii) "os gestores da empresa acreditam que a redução do custo é obtida na fase de projeto de um novo produto". Dentre os respondentes, 31\% afirmaram utilizar o custeio meta e $50 \%$ afirmaram concordar que os gestores percebem que a redução do custo é obtida na fase do projeto do produto. As Tabelas 16 e 17 demonstram esses resultados.

Tabela 16 Respostas relativas à utilização do custeio meta

\begin{tabular}{l|c|c|c|c|c|c}
\hline & \multicolumn{2}{|c|}{ Quantidade de respondentes } & \multicolumn{3}{c}{ Participação \% } \\
\hline & $\begin{array}{c}\text { Empresas } \\
\text { Indicadas }\end{array}$ & $\begin{array}{c}\text { Demais } \\
\text { empresas }\end{array}$ & Total & $\begin{array}{c}\text { Empresas } \\
\text { Indicadas }\end{array}$ & $\begin{array}{c}\text { Demais } \\
\text { empresas }\end{array}$ & Total \\
\hline Concorda totalmente & 1 & 3 & 4 & $3 \%$ & $5 \%$ & $4 \%$ \\
\hline Concorda parcialmente & 7 & 19 & 26 & $24 \%$ & $31 \%$ & $29 \%$ \\
\hline Não concorda nem discorda & 7 & 18 & 25 & $24 \%$ & $30 \%$ & $28 \%$ \\
\hline Discorda parcialmente & 3 & 4 & 7 & $10 \%$ & $7 \%$ & $8 \%$ \\
\hline Discorda totalmente & 11 & 17 & 28 & $38 \%$ & $28 \%$ & $31 \%$ \\
\hline Total & 29 & 61 & 90 & $100 \%$ & $100 \%$ & $100 \%$ \\
\hline
\end{tabular}

Tabela 17 Respostas relativas à crença de que a redução de custos é obtida na fase do projeto do produto

\begin{tabular}{l|c|c|c|c|c|c}
\hline & \multicolumn{2}{|c|}{ Quantidade de respondentes } & \multicolumn{3}{c}{ Participação \% } \\
\hline & $\begin{array}{c}\text { Empresas } \\
\text { Indicadas }\end{array}$ & $\begin{array}{c}\text { Demais } \\
\text { empresas }\end{array}$ & Total & $\begin{array}{c}\text { Empresas } \\
\text { Indicadas }\end{array}$ & $\begin{array}{c}\text { Demais } \\
\text { empresas }\end{array}$ & $\begin{array}{c}\text { Total } \\
\text { Concorda totalmente }\end{array}$ \\
\hline Concorda parcialmente & 7 & 13 & 19 & $21 \%$ & $21 \%$ & $21 \%$ \\
\hline Não concorda nem discorda & 5 & 19 & 26 & $24 \%$ & $31 \%$ & $29 \%$ \\
\hline Discorda parcialmente & 8 & 14 & 19 & $17 \%$ & $23 \%$ & $21 \%$ \\
\hline Discorda totalmente & 3 & 10 & 13 & $10 \%$ & $16 \%$ & $14 \%$ \\
\hline Total & 29 & 61 & 90 & $100 \%$ & $100 \%$ & $100 \%$ \\
\hline
\end{tabular}

Chenhall e Langfield-Smith (1998b) consideram esse artefato como emergente e relatam que, segundo os pesquisados no seu estudo, os benefícios percebidos são irrisórios, o que justifica a baixa utilização. Guilding, Cravens e Tayles (2000) informaram 
que $45 \%$ dos seus entrevistados afirmaram utilizar esse artefato em suas decisões estratégicas. Sulaiman, Ahmad e Alwi (2004) relatam os baixos índices de utilização desse artefato, ou seja, apenas uma das pesquisas relacionadas no seu estudo demonstrou uma utilização de $35 \%$, nas demais, os resultados se aproximaram de zero. O estudo realizado por Soutes e Zen (2005) indica o índice de utilização de $17 \%$ na amostra estudada e o estudo de Szychta (2006) indica que 3,3\% das empresas da amostra utilizam esse instrumento.

\section{Benchmarking}

Foram feitas duas perguntas relativas ao processo de benchmarking: (i) "a empresa acompanha a evolução dos seus indicadores não financeiros" e (ii) "a empresa compara alguns de seus indicadores com os de outras empresas do mesmo setor (benchmarking)". Os resultados são apresentados nas Tabelas 18 e 19.

Tabela 18 Respostas relativas ao acompanhamento dos indicadores não-financeiros

\begin{tabular}{l|c|c|c|c|c|c}
\hline & \multicolumn{2}{|c|}{ Quantidade de respondentes } & \multicolumn{3}{c}{ Participação \% } \\
\hline & $\begin{array}{c}\text { Empresas } \\
\text { Indicadas }\end{array}$ & $\begin{array}{c}\text { Demais } \\
\text { empresas }\end{array}$ & Total & $\begin{array}{c}\text { Empresas } \\
\text { Indicadas }\end{array}$ & $\begin{array}{c}\text { Demais } \\
\text { empresas }\end{array}$ & Total \\
\hline Concorda totalmente & 17 & 25 & 42 & $59 \%$ & $41 \%$ & $47 \%$ \\
\hline Concorda parcialmente & 7 & 25 & 32 & $24 \%$ & $41 \%$ & $36 \%$ \\
\hline Não concorda nem discorda & 4 & 6 & 10 & $14 \%$ & $10 \%$ & $11 \%$ \\
\hline Discorda parcialmente & 0 & 1 & 1 & $0 \%$ & $2 \%$ & $1 \%$ \\
\hline Discorda totalmente & 1 & 4 & 5 & $3 \%$ & $7 \%$ & $6 \%$ \\
\hline Total & 29 & 61 & 90 & $100 \%$ & $100 \%$ & $100 \%$ \\
\hline
\end{tabular}

Tabela 19 Respostas relativas à comparação de indicadores com indicadores de outras empresas

\begin{tabular}{l|c|c|c|c|c|c}
\hline & \multicolumn{2}{|c|}{ Quantidade de respondentes } & \multicolumn{3}{c}{ Participação \% } \\
\hline & $\begin{array}{c}\text { Empresas } \\
\text { Indicadas }\end{array}$ & $\begin{array}{c}\text { Demais } \\
\text { empresas }\end{array}$ & Total & $\begin{array}{c}\text { Empresas } \\
\text { Indicadas }\end{array}$ & $\begin{array}{c}\text { Demais } \\
\text { empresas }\end{array}$ & Total \\
\hline Concorda totalmente & 16 & 35 & 51 & $55 \%$ & $57 \%$ & $57 \%$ \\
\hline Concorda parcialmente & 10 & 15 & 25 & $34 \%$ & $25 \%$ & $28 \%$ \\
\hline Não concorda nem discorda & 2 & 2 & 4 & $7 \%$ & $3 \%$ & $4 \%$ \\
\hline Discorda parcialmente & 1 & 7 & 8 & $3 \%$ & $11 \%$ & $9 \%$ \\
\hline Discorda totalmente & 0 & 2 & 2 & $0 \%$ & $3 \%$ & $2 \%$ \\
\hline Total & 29 & 61 & 90 & $100 \%$ & $100 \%$ & $100 \%$ \\
\hline
\end{tabular}

Os resultados evidenciam que $83 \%$ das empresas utilizam indicadores não financeiros, o que leva a crer que possuem benchmarks internos e $85 \%$ das empresas da amostra utilizam algum tipo de benchmark externo.

Os resultados de estudos anteriores são consistentes com os resultados desta pesquisa. Chenhall e Langfield-Smith (1998b) concluíram que essa prática possui alta adoção entre os seus pesquisados, o mesmo ocorrendo com a pesquisa de Soutes e Zen (2005), a qual observa que $66 \%$ dos seus respondentes utilizam essa prática.

\section{Kaizen}

A popularidade dessa filosofia de gestão pode ser considerada como resultante do boom de implantação dos programas de qualidade total, que, no Brasil, ocor- 
reu nas décadas de 1980 e 1990 . Um terço (33\%) afirmaram concordar com a utilização dessa prática em suas empresas. $\mathrm{O}$ detalhamento dos resultados obtidos é apresentado na Tabela 20. Essa prática foi considerada emergente no estudo de Coad (1999), no qual é relatado que $54,7 \%$ dos respondentes não a utilizam.

Tabela 20 Respostas relativas à utilização do kaizen

\begin{tabular}{l|c|c|c|c|c|c}
\hline & \multicolumn{2}{|c|}{ Quantidade de respondentes } & \multicolumn{3}{c}{ Participação \% } \\
\hline & $\begin{array}{c}\text { Empresas } \\
\text { Indicadas }\end{array}$ & $\begin{array}{c}\text { Demais } \\
\text { empresas }\end{array}$ & Total & $\begin{array}{c}\text { Empresas } \\
\text { Indicadas }\end{array}$ & $\begin{array}{c}\text { Demais } \\
\text { empresas }\end{array}$ & Total \\
\hline Concorda totalmente & 4 & 10 & 14 & $14 \%$ & $16 \%$ & $16 \%$ \\
\hline Concorda parcialmente & 6 & 9 & 15 & $21 \%$ & $15 \%$ & $17 \%$ \\
\hline Não concorda nem discorda & 4 & 15 & 19 & $14 \%$ & $25 \%$ & $21 \%$ \\
\hline Discorda parcialmente & 3 & 4 & 7 & $10 \%$ & $7 \%$ & $8 \%$ \\
\hline Discorda totalmente & 12 & 23 & 35 & $41 \%$ & $38 \%$ & $39 \%$ \\
\hline Total & 29 & 61 & 90 & $100 \%$ & $100 \%$ & $100 \%$ \\
\hline
\end{tabular}

\section{Just-in-Time}

A Tabela 21 evidencia que $31 \%$ das empresas utilizam essa prática

Tabela 21 Respostas relativas à utilização do Just-in-Time

\begin{tabular}{l|c|c|c|c|c|c}
\hline & \multicolumn{2}{|c|}{ Quantidade de respondentes } & \multicolumn{3}{c}{ Participação \% } \\
\hline & $\begin{array}{c}\text { Empresas } \\
\text { Indicadas }\end{array}$ & $\begin{array}{c}\text { Demais } \\
\text { empresas }\end{array}$ & Total & $\begin{array}{c}\text { Empresas } \\
\text { Indicadas }\end{array}$ & $\begin{array}{c}\text { Demais } \\
\text { empresas }\end{array}$ & Total \\
\hline Concorda totalmente & 1 & 11 & 12 & $3 \%$ & $18 \%$ & $13 \%$ \\
\hline Concorda parcialmente & 5 & 11 & 16 & $17 \%$ & $18 \%$ & $18 \%$ \\
\hline Não concorda nem discorda & 4 & 13 & 17 & $14 \%$ & $21 \%$ & $19 \%$ \\
\hline Discorda parcialmente & 3 & 5 & 8 & $10 \%$ & $8 \%$ & $9 \%$ \\
\hline Discorda totalmente & 16 & 21 & 37 & $55 \%$ & $34 \%$ & $41 \%$ \\
\hline Total & 29 & 61 & 90 & $100 \%$ & $100 \%$ & $100 \%$ \\
\hline
\end{tabular}

Durden, Hassel e Upton (1999), com uma amostra de empresas da Nova Zelândia, demonstraram que $36 \%$ das empresas têm utilizado essa prática. As pesquisas empíricas em países asiáticos, reportadas no estudo de $\mathrm{Su}$ laiman, Ahmad e Alwi (2004), demonstram um grau mínimo de utilização de conceito nas empresas pesquisadas. Hoque (2000) descobriu que, em escala Likert de cinco pontos, a média de respostas positivas foi 2,99 (com mediana 3) em amostra de empresas na Nova Zelândia.

\section{Teoria das restrições}

Um dos indicadores-chave da teoria das restrições (NOREEN; SMITH; MACKEY, 1995) é o ganho ou margem de contribuição por fator restritivo. A verificação da utilização desse indicador deu-se pelo seguinte questionamento: "a empresa avalia a margem de contribuição por fator limitante de produção”. O resultado evidencia que $52 \%$ das empresas trabalham com o conceito de margem de contribuição por fator limitante. O detalhe das respostas obtidas é apresentado na Tabela 22. 
Tabela 22 Respostas relativas à utilização da margem de contribuição por fator limitante de produção

\begin{tabular}{l|c|c|c|c|c|c}
\hline & \multicolumn{2}{|c|}{ Quantidade de respondentes } & \multicolumn{3}{c}{ Participação \% } \\
\hline & $\begin{array}{c}\text { Empresas } \\
\text { Indicadas }\end{array}$ & $\begin{array}{c}\text { Demais } \\
\text { empresas }\end{array}$ & Total & $\begin{array}{c}\text { Empresas } \\
\text { Indicadas }\end{array}$ & $\begin{array}{c}\text { Demais } \\
\text { empresas }\end{array}$ & Total \\
\hline Concorda totalmente & 5 & 11 & 16 & $17 \%$ & $18 \%$ & $18 \%$ \\
\hline Concorda parcialmente & 9 & 22 & 31 & $31 \%$ & $36 \%$ & $34 \%$ \\
\hline Não concorda nem discorda & 6 & 12 & 18 & $21 \%$ & $20 \%$ & $20 \%$ \\
\hline Discorda parcialmente & 2 & 3 & 5 & $7 \%$ & $5 \%$ & $6 \%$ \\
\hline Discorda totalmente & 7 & 13 & 20 & $24 \%$ & $21 \%$ & $22 \%$ \\
\hline Total & 29 & 61 & 90 & $100 \%$ & $100 \%$ & $100 \%$ \\
\hline
\end{tabular}

\section{Custo Financeiro dos Estoques}

A mensuração do custo financeiro tem sido desenvolvida no âmbito do modelo de Gestão Econômica (CATELLI, 2001), bem como em diversos modelos de mensuração de custos logísticos (LAMBERT; BURDUROGLU, 2000). A verificação da utilização desse conceito deu- se pela indagação: "a empresa calcula o custo financeiro dos estoques". Os resultados, apresentados na Tabela 23, demonstram que 56\% das empresas respondentes afirmaram calcular o custo financeiro de estoques. Não foram encontradas outras pesquisas que apresentem índices de utilização dessa prática.

Tabela 23 Respostas relativas ao cálculo do custo financeiro dos estoques

\begin{tabular}{l|c|c|c|c|c|c}
\hline & \multicolumn{2}{|c|}{ Quantidade de respondentes } & \multicolumn{3}{c}{ Participação \% } \\
\hline & $\begin{array}{c}\text { Empresas } \\
\text { Indicadas }\end{array}$ & $\begin{array}{c}\text { Demais } \\
\text { empresas }\end{array}$ & Total & $\begin{array}{c}\text { Empresas } \\
\text { Indicadas }\end{array}$ & $\begin{array}{c}\text { Demais } \\
\text { empresas }\end{array}$ & Total \\
\hline Concorda totalmente & 6 & 21 & 27 & $21 \%$ & $34 \%$ & $30 \%$ \\
\hline Concorda parcialmente & 11 & 12 & 23 & $38 \%$ & $20 \%$ & $26 \%$ \\
\hline Não concorda nem discorda & 2 & 7 & 9 & $7 \%$ & $11 \%$ & $10 \%$ \\
\hline Discorda parcialmente & 3 & 1 & 4 & $10 \%$ & $2 \%$ & $4 \%$ \\
\hline Discorda totalmente & 7 & 20 & 27 & $24 \%$ & $33 \%$ & $30 \%$ \\
\hline Total & 29 & 61 & 90 & $100 \%$ & $100 \%$ & $100 \%$ \\
\hline
\end{tabular}

\section{Economic Value Added (EVA)}

A verificação da utilização do EVA foi efetuada com a afirmação: "A empresa utiliza o EVA para avaliar seu desempenho econômi- co". Como é demonstrado na Tabela 24, 50\% dos respondentes concordaram com a utilização dessa prática.

Tabela 24 Respostas relativas à utilização do Economic Value Added (EVA)

\begin{tabular}{l|c|c|c|c|c|c}
\hline & \multicolumn{2}{|c|}{ Quantidade de respondentes } & \multicolumn{3}{c}{ Participação \% } \\
\hline & $\begin{array}{c}\text { Empresas } \\
\text { Indicadas }\end{array}$ & $\begin{array}{c}\text { Demais } \\
\text { empresas }\end{array}$ & Total & $\begin{array}{c}\text { Empresas } \\
\text { Indicadas }\end{array}$ & $\begin{array}{c}\text { Demais } \\
\text { empresas }\end{array}$ & Total \\
\hline Concorda totalmente & 11 & 22 & 33 & $38 \%$ & $36 \%$ & $37 \%$ \\
\hline Concorda parcialmente & 6 & 6 & 12 & $21 \%$ & $10 \%$ & $13 \%$ \\
\hline Não concorda nem discorda & 4 & 8 & 12 & $14 \%$ & $13 \%$ & $13 \%$ \\
\hline Discorda parcialmente & 2 & 3 & 5 & $7 \%$ & $5 \%$ & $6 \%$ \\
\hline Discorda totalmente & 6 & 22 & 28 & $21 \%$ & $36 \%$ & $31 \%$ \\
\hline Total & 29 & 61 & 90 & $100 \%$ & $100 \%$ & $100 \%$ \\
\hline
\end{tabular}


Os resultados deste estudo são bastante superiores aos obtidos no estudo de Soutes e Zen (2005), que indica que 25\% das empresas da amostra utilizam EVA para avaliar desempenho econômico. Os resultados da pesquisa de Frezatti (2005) indicam um nível de aderência entre a prática e a teoria em torno de $29 \%$.

\section{Simulações}

Foram inseridas duas questões relativas à utilização de simulações: (i) "são realizadas simulações de rentabilidade dos produtos (Receitas, Custos e Margem)" e (ii) "a empresa possui software específico para fazer simulação de resultados”. As Tabelas 25 e 26 demonstram que $88 \%$ das empresas da amostra realizam simulações de rentabilidade, enquanto $58 \%$ das empresas possuem softwares específicos para realizar tais simulações.

Tabela 25 Respostas relativas à simulação de resultados de produtos

\begin{tabular}{l|c|c|c|c|c|c}
\hline & \multicolumn{2}{|c|}{ Quantidade de respondentes } & \multicolumn{3}{c}{ Participação \% } \\
\hline & $\begin{array}{c}\text { Empresas } \\
\text { Indicadas }\end{array}$ & $\begin{array}{c}\text { Demais } \\
\text { empresas }\end{array}$ & Total & $\begin{array}{c}\text { Empresas } \\
\text { Indicadas }\end{array}$ & $\begin{array}{c}\text { Demais } \\
\text { empresas }\end{array}$ & Total \\
\hline Concorda totalmente & 20 & 40 & 60 & $69 \%$ & $66 \%$ & $67 \%$ \\
\hline Concorda parcialmente & 7 & 12 & 19 & $24 \%$ & $20 \%$ & $21 \%$ \\
\hline Não concorda nem discorda & 1 & 6 & 7 & $3 \%$ & $10 \%$ & $8 \%$ \\
\hline Discorda parcialmente & 1 & 2 & 3 & $3 \%$ & $3 \%$ & $3 \%$ \\
\hline Discorda totalmente & 0 & 1 & 1 & $0 \%$ & $2 \%$ & $1 \%$ \\
\hline Total & 29 & 61 & 90 & $100 \%$ & $100 \%$ & $100 \%$ \\
\hline
\end{tabular}

Tabela 26 Respostas relativas à utilização de software específico para a simulação de resultados

\begin{tabular}{l|c|c|c|c|c|c}
\hline & \multicolumn{2}{|c|}{ Quantidade de respondentes } & \multicolumn{3}{c}{ Participação \% } \\
\hline & $\begin{array}{c}\text { Empresas } \\
\text { Indicadas }\end{array}$ & $\begin{array}{c}\text { Demais } \\
\text { empresas }\end{array}$ & Total & $\begin{array}{c}\text { Empresas } \\
\text { Indicadas }\end{array}$ & $\begin{array}{c}\text { Demais } \\
\text { empresas }\end{array}$ & Total \\
\hline Concorda totalmente & 9 & 25 & 34 & $31 \%$ & $41 \%$ & $38 \%$ \\
\hline Concorda parcialmente & 6 & 12 & 18 & $21 \%$ & $20 \%$ & $20 \%$ \\
\hline Não concorda nem discorda & 4 & 10 & 14 & $14 \%$ & $16 \%$ & $16 \%$ \\
\hline Discorda parcialmente & 3 & 7 & 10 & $10 \%$ & $11 \%$ & $11 \%$ \\
\hline Discorda totalmente & 7 & 7 & 14 & $24 \%$ & $11 \%$ & $16 \%$ \\
\hline Total & 29 & 61 & 90 & $100 \%$ & $100 \%$ & $100 \%$ \\
\hline
\end{tabular}

Sulaiman, Ahmad e Alwi (2004) demonstram que a simulação de rentabilidade (análise de relação entre o custo, o volume e o lucro) é uma prática muito empregada nas empresas pesquisadas na Ásia, com percentuais de utilização acima de 55\%.

\section{Balanced Scorecard (BSC)}

O BSC utiliza uma combinação de indicadores monetários e de indicadores não monetários sintonizados com as estratégias de longo prazo de várias dimensões da gestão da empresa (KAPLAN, 2006; MALMI, 2001). Para verificar se as empresas estão ou não utilizando esse artefato, foi feita a indagação "a empresa utiliza o Balanced Scorecard". Como demonstrado na Tabela 27 abaixo, 46\% das empresas respondentes declararam que utilizam o BSC. 
Tabela 27 Respostas relativas à utilização do Balanced Scorecard

\begin{tabular}{l|c|c|c|c|c|c}
\hline & \multicolumn{2}{|c|}{ Quantidade de respondentes } & \multicolumn{3}{c}{ Participação \% } \\
\hline & $\begin{array}{c}\text { Empresas } \\
\text { Indicadas }\end{array}$ & $\begin{array}{c}\text { Demais } \\
\text { empresas }\end{array}$ & Total & $\begin{array}{c}\text { Empresas } \\
\text { Indicadas }\end{array}$ & $\begin{array}{c}\text { Demais } \\
\text { empresas }\end{array}$ & Total \\
\hline Concorda totalmente & 9 & 15 & 24 & $31 \%$ & $25 \%$ & $27 \%$ \\
\hline Concorda parcialmente & 4 & 13 & 17 & $14 \%$ & $21 \%$ & $19 \%$ \\
\hline Não concorda nem discorda & 3 & 7 & 10 & $10 \%$ & $11 \%$ & $11 \%$ \\
\hline Discorda parcialmente & 2 & 3 & 5 & $7 \%$ & $5 \%$ & $6 \%$ \\
\hline Discorda totalmente & 11 & 23 & 34 & $38 \%$ & $38 \%$ & $38 \%$ \\
\hline Total & 29 & 61 & 90 & $100 \%$ & $100 \%$ & $100 \%$ \\
\hline
\end{tabular}

Chenhall e Langfield-Smith (1998a, 1998b) consideram o BSC como um artefato "emergente" com índice de utilização moderado. Sulaiman, Ahmad e Alwi (2004) relatam baixos índices de utilização (13\%) entre empresas da Malásia e níveis mais altos de utilização (40\%) em empresas da Índia. Soutes e Zen (2005) reportam que o índice de utilização foi de $27 \%$ entre as empresas da sua amostra. Os resultados da pesquisa de Frezatti (2005) indicam nível de aderência entre a prática e a teoria em torno de $15 \%$.

\subsection{Análise da utilização de artefatos modernos pelos grupos de empresas}

Para avaliar a utilização de artefatos modernos, as duas respostas positivas ("concorda totalmente" e "concorda parcialmente") foram somadas. A Tabela 28 demonstra esses totais de respostas positivas relativas ao uso de artefatos modernos de Contabilidade Gerencial.

Tabela 28 Respostas relativas à utilização de artefatos modernos

\begin{tabular}{l|c|c|c|c|c|c}
\hline & \multicolumn{2}{|c|}{ Quantidade de respondentes } & \multicolumn{3}{c}{ Participação \% } \\
\hline & $\begin{array}{c}\text { Empresas } \\
\text { Indicadas }\end{array}$ & $\begin{array}{c}\text { Demais } \\
\text { empresas }\end{array}$ & Total & $\begin{array}{c}\text { Empresas } \\
\text { Indicadas }\end{array}$ & $\begin{array}{c}\text { Demais } \\
\text { empresas }\end{array}$ & Total \\
\hline $\begin{array}{l}\text { Custeio Baseado em Ativida- } \\
\text { des (ABC) }\end{array}$ & 5 & 22 & 27 & $17 \%$ & $36 \%$ & $30 \%$ \\
\hline Custeio Meta (Target costing) & 8 & 22 & 30 & $27 \%$ & $36 \%$ & $33 \%$ \\
\hline Benchmarking & 26 & 50 & 76 & $89 \%$ & $82 \%$ & $85 \%$ \\
\hline Kaizen & 10 & 19 & 29 & $35 \%$ & $31 \%$ & $33 \%$ \\
\hline Just in Time & 6 & 22 & 28 & $20 \%$ & $36 \%$ & $31 \%$ \\
\hline Teoria das Restrições & 14 & 33 & 47 & $48 \%$ & $54 \%$ & $52 \%$ \\
\hline Custo Financeiro dos Estoques & 17 & 33 & 50 & $59 \%$ & $54 \%$ & $56 \%$ \\
\hline Economic Value Added (EVA) & 27 & 28 & 45 & $59 \%$ & $46 \%$ & $50 \%$ \\
\hline Simulações & 13 & 28 & 41 & $45 \%$ & $46 \%$ & $46 \%$ \\
\hline Balanced Scorecard & 29 & 61 & 90 & $100 \%$ & $100 \%$ & $100 \%$ \\
\hline Total de empresas & & & & & $83 \%$ & $88 \%$ \\
\hline
\end{tabular}

Os resultados indicam que as empresas da amostra estudada utilizam artefatos modernos de Contabilidade Gerencial, embora a intensidade de uso possa variar entre os arte- fatos pesquisados.

Conforme pode ser observado na Tabela 28, os artefatos que apresentam maiores índices de utilização são simulações (88\%) e ben- 
chmarking com $85 \%$. Em um bloco intermediário de utilização, nas empresas da amostra estudada, destacam-se custo financeiro dos estoques (56\%), teoria das restrições (52\%), EVA (50\%) e balanced scorecard (46\%). No terceiro bloco com menor índice de utilização, despontam o custeio meta, kaizen, justin-time e custeio baseado em atividades.

Os resultados do estudo, também, indicam que, na amostra analisada, não existem evidências de que as empresas do grupo "indicadas para o prêmio" utilizem com mais intensidade artefatos modernos de Contabilidade Gerencial do que as do grupo "demais empresas", conforme será discutido na seção seguinte.

\subsection{Comparação de médias}

Adicionalmente aos resultados obtidos com base na análise descritiva, foi desenvolvido um conjunto de testes de hipóteses, objetivando a comparação de médias apresentadas pelos dois grupos de empresas estudadas. Inicialmente, foram analisados os indicadores financeiros de ambos os grupos, com a premissa de que as companhias indicadas apresentariam maiores médias $\left(\mathrm{H}_{1}\right)$. Com base no emprego de testes- $t$ unidirecionais para cada um dos indicadores selecionados (empregados, lucro líquido, patrimônio líquido, ativos, passivos, receitas, variação anual do lucro líquido variação anual do patrimônio líquido, retorno sobre ativo e retorno sobre patrimônio líquido), foi verificado que quatro dentre treze indicadores selecionados são maiores no grupo de empresas indicadas: lucro líquido $(t(82)=-2.779, p=0.003$, unidirecional), patrimônio líquido $(t(82)=-3.194, p=$ 0.001 , unidirecional), ativos $(t(82)=-3.538$, $p=0.000$, unidirecional $)$, e receitas $(t(82)=$ $-2.890, p=0.002$, unidirecional).

Outro conjunto de testes-t unidirecionais foi desenvolvido para checar se as companhias indicadas apresentam, de forma significativa, maior uso de cada instrumento de Contabilidade Gerencial quando comparadas com as empresas do outro grupo $\left(\mathrm{H}_{2}\right)$. Os achados do estudo demonstram que somente um item (constante da lista de artefatos tradicionais) apresentou maior média no grupo de empresas indicadas: $\mathrm{Q}_{42}$ ou "preço de transferência - questão 2 " $(t(88)=-2.138, p=0.017$, unidirecional).

No que diz respeito à investigação se companhias indicadas apresentam de forma significativa maior uso de artefatos tradicionais de Contabilidade Gerencial quando comparadas com as empresas do outro grupo $\left(\mathrm{H}_{3}\right)$, nenhuma evidência significativa foi encontrada $(t(88)=-0.279, p=0.391$, unidirecional $)$. Resultado similar foi obtido na investigação se as companhias indicadas demonstram maior uso de artefatos modernos de Contabilidade Gerencial quando comparadas com as empresas do outro grupo $\left(\mathrm{H}_{4}\right)$ : não foi verificada nenhuma evidência significativa $(t(88)=$ 0.581, $p=0.281$, unidirecional). Com base nesses resultados são rejeitadas as hipóteses nulas $\left(\mathrm{H}_{1}\right)$ e $\left(\mathrm{H}_{2}\right)$ e aceitas as hipóteses nulas $\left(\mathrm{H}_{3}\right)$ e $\left(\mathrm{H}_{4}\right)$.

\section{CONCLUSÕES}

Dois motivos fundamentais justificaram a realização desta pesquisa. $\mathrm{O}$ primeiro diz respeito aos resultados de diversos estudos empíricos que indicam o baixo grau de utilização pelas empresas de artefatos modernos de Contabilidade Gerencial propostos pela teoria. $\mathrm{O}$ segundo elemento motivador é que, no âmbito teórico contabilidade, destaca-se o pressuposto de que a contabilidade deveria atender eficazmente os seus usuários externos e internos. A partir dessas motivações, foram estabelecidos dois objetivos de pesquisa.

O primeiro objetivo foi verificar se empresas brasileiras de uma amostra selecionada que se destacam pelo seu porte na economia brasileira utilizam artefatos modernos de 
Contabilidade Gerencial. O segundo objetivo diz respeito a investigar se empresas de uma amostra selecionada que se destacam pela qualidade de suas informações aos usuários externos também se destacariam no atendimento de seus usuários internos.

No que diz respeito ao primeiro objetivo deste estudo, por meio da análise descritiva dos resultados é possível inferir que as empresas da amostra estudada utilizam artefatos modernos de Contabilidade Gerencial. Deve ser observado que a intensidade da utilização varia de artefato para artefato e que mesmo os artefatos com menor uso, tais como just-intime, kaizen e target costing, são empregados por mais de 30\% das empresas estudadas.

No que diz respeito ao segundo objetivo, os dados da amostra demonstram que o grupo de empresas indicadas ao Prêmio ANEFAC-FIPECAFI-SERASA (Troféu Transparência) não se diferencia do grupo das demais empresas pesquisadas. Deve ser observado que não é possível com os resultados encontrados afirmar que as empresas estudadas não estão atendendo, adequadamente, seus usuários internos. Para a amostra estudada pode-se inferir que empresas que se sobressaem pela qualidade das informações prestadas para usuários externos não se diferenciam das demais empresas com relação ao uso de artefatos modernos de contabilidade. Essa conclusão pode ser obtida com a análise de médias dos dois grupos de empresas no teste da hipótese $\mathrm{H}_{4}$.

Algumas limitações deste estudo devem ser observadas. O tipo de pesquisa efetuada (não probabilística) significa que os resultados são válidos apenas para a amostra estudada $\mathrm{e}$ devem ser utilizados com cuidado. Adicionalmente, devem-se considerar as características do grupo de empresas (grupo diferenciado pelo porte e importância). Dessa forma, é preciso atenção na extrapolação dos resultados deste estudo e nas comparações diretas com resultados de outros estudos relativos à utilização de artefatos de Contabilidade Gerencial. A restrição deste estudo abre possibilidades para pesquisas futuras sobre este tema, tais como: (i) o desenvolvimento de pesquisa probabilística mais abrangente sobre o tema e (ii) a consideração sobre quais artefatos são mais utilizados por setor econômico.

\section{Referências}

ABDEL-KADER, M.; LUTHER, R. The impact of firm characteristics on management accounting practices: a UK-based empirical analysis. The British Accounting Review, v. 40, p. 2-27, 2008.

ADELEGAN, O. J. Management accounting practices in Nigerian companies. Disponível no site do IFAC em: <http://www.ifac.org/Library/SpeechArticle. tmpl?NID=99721684027547>. Acesso em: 03 maio 2006 ASK, U.; AX, C. Trends in the development of product costing practices and techniques - a survey of Swedish manufacturing industry. In: ANNUAL CONGRESS OF THE EUROPEAN ACCOUNTING ASSOCIATION, 15. 1992, Madri. Anais... Madri, 1992.

BAINES, A.; LANGFIELD-SMITH, K. Antecedents to management accounting change: a structural equation approach. Accounting, Organization and Society, v. 28, p. 675-698, 2003.

BEUREN, I. M.; ERFURTH A. E. Pesquisa em contabilidade gerencial com base no futuro realizada no Brasil. Contabilidade, Gestão e Governança, v. 13, n. 1, p. 44-58, 2010.

BJORNENAK, T. Conventional wisdom and costing practices. Management Accounting Research, n. 8, p. 367-382, 1997.

BJORNENAK, T.; OLSON, O. Unbundling management accounting innovations. Management Accounting Research, n. 10, p. 325-338, 1999.

BRIGTH, J.; DAVIES, R. E.; DOWNES, C. A.;

SWEETING, R. C. The deployment of costing techniques and practices: a UK study. Management Accounting, v. 3, p. 201-212, 1992.

CAGWIN, D.; BOUWMAN, M. The association between activity-based costing and improvement in financial performance. Management Accounting Research, n. 13, p. 1-39, 2002.

CARDOSO, R. L.; PEREIRA, C. A.; GUERREIRO,

R. Perfil das pesquisas em contabilidade de custos apresentadas no EnANPAD no período de 1998 a 2003. Revista de Administração Contemporânea, v. 11, n. 3, p. 177-198, 2007.

CARR, S.; MAK, Y. T.; NEEDHAM, J. E. Differences in strategy, quality management practices and performance reporting systems between ISO accredited an non-ISO accredited companies. Management Accounting Research, 
n. 8, p. 383-403, 1997.

CATELLI, A. Controladoria: uma abordagem da gestão econômica. 2. ed. São Paulo: Atlas, 2001.

CHENHALL, R. H.; LANGFIELD-SMITH, K. Adoption and benefits of management accounting practices: an Australian study. Management Accounting Research, n. 9, p. 1-19, 1998c.

Factors influencing the role of management accounting in the development of performance measures within organizational change programs. Management Accounting Research, n. 9, p. 361-386, 1998a.

The relationship between strategic priorities, management techniques and management accounting: an empirical investigation using a systems approach. Accounting, Organizations and Society, v. 23, n. 3, p. 243 264, 1998 b.

CHOUDHURY, N. In search of relevance in management accounting research. Accounting and Business Research, p. 21-26, winter 1986.

COAD, A. F. Some survey evidence on the learning and performance orientations of management accountants. Management Accounting Research, n. 10, p. 109-135, 1999. COHEN, J. R.; PAQUETTE, L. Management accounting practices: perceptions of controllers. Journal of Cost Management for the Manufacturing Industry, p. 73-83, 1991.

DRURY, C.; BRAUND, S.; OSBORNE, P.; TAYLEST, M. A survey of management accounting practices in UK manufacturing companies. Chartered Association of Certified Accountants, 1993.

; TAYLES, M. Issues arising from surveys of management accounting practices. Management Accounting Review, n. 6, p. 267-280, 1995. DURDEN, C. H.; HASSEL, L. G.; UPTON, D. R. Cost accounting and performance measurement in a just-intime production environment. Asia Pacific Journal of Management, v. 16, n. 1, p. 111-125, 1999.

EDWARDS, K. A.; EMMANUEL, C. R. Diverging views on the boundaries of management accounting. Management Accounting Research, v. 1, n. 1, p. 551-563, 1990.

EMORE, J. R.; NESS, J. A. The slow pace of meaningful changes in cost systems. Journal of Cost Management for the Manufacturing Industry, p. 36-45, winter 1991.

EVANS, H.; ASHWORTH, G. Survey conclusion: make up to the competition. Management Accounting, UK, v. 74, p. 16-18, 1996.

FREZATTI, F. Management accounting profile of firms located in Brazil: a field study. Brazilian Administration Review, n. 1, v. 2, p. 73-87, 2005.

GARG, A. et al. Roles and practices management. Strategic Finance, p. 30-35, 2003.

GRANLUND, M. Towards explaining stability in and around management accounting systems. Management Accounting Research, v. 12, p. 141-146, 2001.

; LUKKA, K. It's a small world of management

accounting practices. Journal of Management Accounting Research, n. 10, p. 153-179, 1998.

GREEN, F. B.; AMENKHIENAN, F. E. Accounting inovations: a cross sectional survey of manufacturing firms. Journal of Cost Management for the Manufacturing Industry, spring 1992.

GUILDING, C.; CRAVENS, K. S.; TAYLES, M. An international comparison of strategic management practices. Management Accounting Research, n. 11, p. 113-135, 2000.

HALDMA, T.; LÄÄTS, K. Contingencies influencing the management accounting practices of Estonian manufacturing companies. Management Accounting Research, n. 13, p. 379-400, 2002.

HENDRIKSEN, E. S.; VAN BREDA, M. F. Accounting theory. 5. ed. Richard D. Irwin, 1992.

HIMME, A. Cost management projects in Germany. Cost Management, v. 24, p. 24-33, 2010.

HOQUE, Z. Just-in-time- production, automation, cost allocation practices and importance of cost information: an empirical investigation in New Zealand-based manufacturing organizations. British Accounting Review, n. 32, p. 133-159, 2000.

HORNGREN, C. T.; FOSTER, G.; DATAR, S. M. Cost accounting: a managerial emphasis. 10. ed. Upper Saddle River, NJ: Prentice Hall, 2000.

HUGHES, S. B.; GJERDE, K. A. P. Do different cost systems make a difference? Management Accounting Quarterly, Montvale, v. 1, n. 5, p. 22-30, 2003.

INNES, J.; MITCHELL, F.; SINCLAIR, D. Activity-based costing in the U.K.'s largest companies: a comparison of 1994 and 1999 survey results. Management Accounting Research, n. 11, p. 349-362, 2000.

INTERNATIONAL FEDERATION OF ACCOUNTANTS (IFAC). International management accounting practice statement: management accounting concepts, mar. 1998.

IUDÍCIBUS, S. Teoria da Contabilidade. 5. ed. São Paulo: Atlas, 1997.

JOHNSON, H. T.; KAPLAN, R. S. Relevance lost-the rise and fall of management accounting. Boston: Harvard Business School Press, 1987.

KAPLAN, R. S. The competitive advantage of management accounting. Journal of Management Accounting Research, n. 18, p. 127-135, 2006.

LAMBERT, D. M.; BURDUROGLU, R. Measuring and selling the value of logistics. International Journal of Logistics Management, v. 11, n. 1, p. 1-17, 2000.

MAHER, M. W. Management accounting education at the millennium. Issues in Accounting Education, v. 15, n. 2, p. 335-346, 2000.

MALMI, T. Balanced scorecards in finnish companies: a research note. Management Accounting Research, n. 12, p 207-220, 2001.

McNAIR, C. J. Beyond the boundaries: future trends in cost management. Cost Management, n. 21, p. 10-21, jan./feb. 2007.

NOREEN, E.; SMITH, D.; MACKEY, J. T. The theory of constraints and its implications for management accounting. Great Barrington: The North River Press Publishing Corporation, 1995.

OTLEY, D. T. Developments in management accounting research. Management Accounting, p. 37-42, sep. 1985.

OYADOMARI, J. C. T.; CARDOSO, R. L.; 
MENDONÇA, O. R.; LIMA, M. P. Fatores que influenciam a adoção de artefatos de controle gerencial nas empresas brasileiras. Um estudo exploratório sob a ótica da teoria neo-institucional. Revista de Contabilidade e Organizações, v. 2, n. 2, p. 55-70, 2008. SANTOS, C. A.; COSTA, F. M. G.; ESPEJO, M. M. S. B.; PANHOCA, L. A influência do estilo gerencial na adoção dos artefatos de controle gerencial nas organizações sem fins lucrativos de Curitiba do setor do meio ambiente. Revista ADMpg Gestão Estratégica, Ponta Grossa, v. 2, n. 2, p. 77-86, 2009.

SCAPENS, R. W. Never mind the gap: towards an institutional perspective on management practice. Management Accounting Research, n. 5, p. 301-321, 1994.

SHIELDS, M. D. Research in Management Accounting by North Americans in the 1990s. Journal of Management Accounting Research, v. 9, 1997. SOUTES, D. O.; ZEN, M. J. C. M. Estágios evolutivos da contabilidade gerencial em empresas brasileiras.
In: CONGRESSO USP DE CONTROLADORIA E CONTABILIDADE, 5., 2005, São Paulo. Anais... São Paulo, 2005.

SULAIMAN, M. bt.; AHMAD, N. N. N.; ALWI, N. Management accounting practices in selected Asian countries: a review of the literature. Managerial Auditing Journal, v. 4, n. 19, p. 493-508, 2004.

SZYCHTA, A. Development of management accounting practice in Poland. In: CONFERENCE ON NEW DIRECTIONS IN MANAGEMENT ACCOUNTING: INNOVATIONS IN PRACTICE AND RESEARCH, 5., 2006, Bruxelas. Anais... Bruxelas, 2006.

TEIXEIRA, A. J. C.; GONZAGA, R. P.; SANTOS, A. V. S. M.; NOSSA, V. A utilização de ferramentas de contabilidade gerencial nas empresas do Estado do Espírito Santo. In: INTERNATIONAL ASSOCIATION FOR ACCOUNTING EDUCATION AND RESEARCH AND ASSOCIAÇÃO NACIONAL DE PÓS-

GRADUAÇÃO EM CIÊNCIAS CONTÁBEIS, 3., 2009, São Paulo. Anais... São Paulo, 2009. 